\author{
Marquette University \\ e-Publications@Marquette
}

Dissertations (1934 -)

Dissertations, Theses, and Professional

Projects

\title{
Military Mental Health: Problem Recognition, Treatment-Seeking, and Barriers
}

Laura Bein

Marquette University

Follow this and additional works at: https://epublications.marquette.edu/dissertations_mu

Part of the Clinical Psychology Commons

Recommended Citation

Bein, Laura, "Military Mental Health: Problem Recognition, Treatment-Seeking, and Barriers" (2011).

Dissertations (1934 -). 147.

https://epublications.marquette.edu/dissertations_mu/147 


\title{
MILITARY MENTAL HEALTH: PROBLEM RECOGNITION, TREATMENT- SEEKING, AND BARRIERS
}

\author{
by \\ Laura Bein, M.S.
}

A Dissertation submitted to the Faculty of the Graduate School, Marquette University,

in Partial Fulfillment of the Requirements for the Degree of Doctor of Philosophy

Milwaukee, Wisconsin

December 2011 


\title{
ABSTRACT \\ MILITARY MENTAL HEALTH: PROBLEM RECOGNITION, TREATMENT- SEEKING, AND BARRIERS
}

\author{
Laura Bein, M.S.
}

Marquette University, 2011

Substantial numbers of military troops are serving overseas in military operations and are returning home with elevated reports of psychological symptoms; however, a treatment gap exists between those reporting mental health problems and those receiving appropriate treatment. Stigma has been cited as a potential barrier to treatment-seeking, although few studies distinguish between perceived and public stigma or between stigma for having a mental illness versus that for seeking treatment.

In the present study, Army National Guard soldiers returning from deployment to Iraq were asked to complete questionnaires assessing psychological symptoms, as well as reports of perceived stigma from self and others for admitting the presence of a mental illness and for seeking treatment. Soldiers also reported the likelihood that they would seek treatment and indicated perceived barriers to treatment.

Results showed that respondents reported more perceived stigma from self and military others than from civilian others for most stigma items (both for admitting a mental illness and seeking treatment). A combination of demographic and stigma variables were found to be predictive of a higher reported likelihood of seeking treatment. Veterans also endorsed a number of barriers that may prevent them from seeking treatment in addition to concerns about stigma.

Perceptions of both self- and public stigma appear to be associated with a lower likelihood of admitting and seeking treatment for a mental illness among soldiers, although much is unknown about additional factors contributing to the treatment gap. Further research clarifying these additional factors is necessary for the improved access to psychological care that may be needed by a substantial number of military personnel returning from deployment. 


\title{
ACKNOWLEDGMENTS
}

\author{
Laura Bein, M.S.
}

First and foremost, I would like to thank Dr. Stephen Saunders for his support and guidance throughout my years at Marquette. His words of encouragement, sense of humor, and advice were essential not only to my development as a clinician but to the maintenance of my sanity throughout graduate school. I would also like to thank my dissertation committee members for their helpful feedback in the completion of this project. Thank you to Dr. Terri deRoon-Cassini and Dr. Bill Lorber, without whom I could not have been part of this project.

I would also like to thank my family, who have been such a supportive and motivating force during my graduate training. To Michaela, thank you for being a constant source of true happiness (even in my times of stress) and a reminder of what is important since you arrived. To my parents, Amy, and Jacob, thank you for all of your words of encouragement and for riding the rollercoaster of the last several years with me. To my friend Sara, thank you for being a listening ear as we navigated graduate school together, and for the dissertation dates.

Finally, to my husband, Tim... thank you for helping relieve my stress, for helping me remember my values and priorities, and for all you have done to allow me to complete my goals. Substantially more important than that, thank you for your service and for coming home safely five years ago. 


\section{TABLE OF CONTENTS}

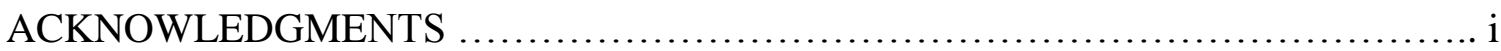

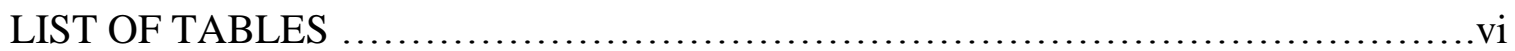

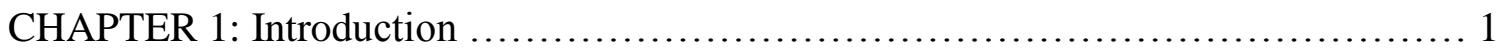

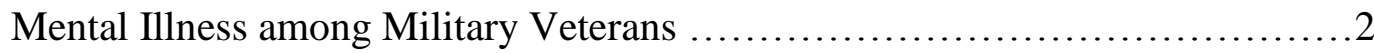

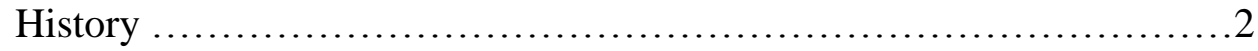

The Conflict in Vietnam......................................... 3

Mental Illness among OIF/OEF Veterans ..........................4

Effects of Mental Illness on Veterans ................................

Effectiveness of Mental Health Treatment among Veterans ................... 9

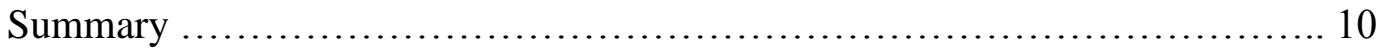

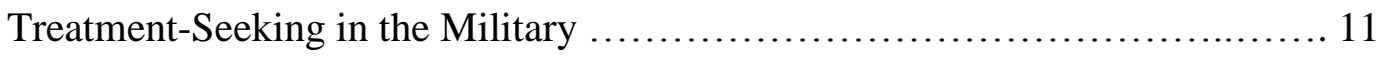

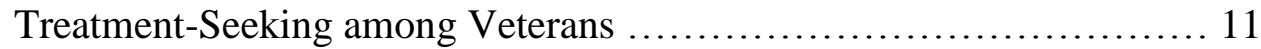

Barriers to Seeking Treatment among Veterans ..................... 14

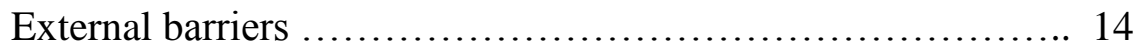

Personal barriers ............................................ 14

Self-stigma in the military ............................. 15

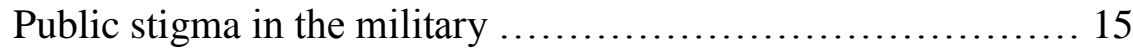

The association between self-stigma and public stigma ......... 21

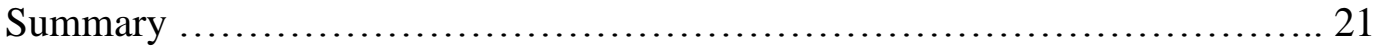

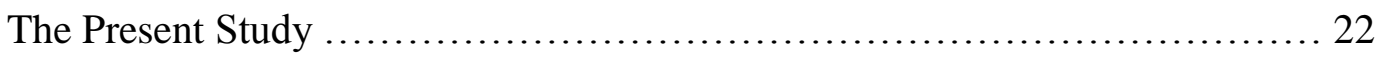

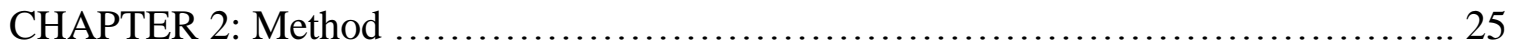

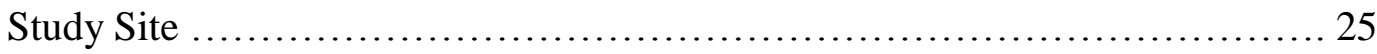


Participants ..................................................... 26

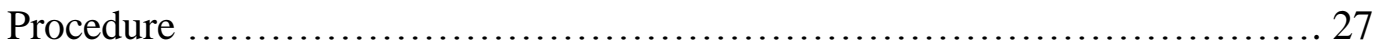

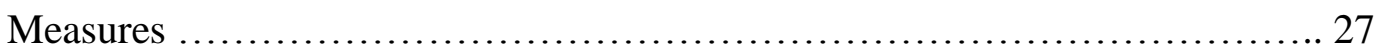

PTSD Checklist- Civilian Version $($ PCL-C) $\ldots \ldots \ldots \ldots \ldots \ldots \ldots \ldots \ldots \ldots$

Consequences of acknowledging a mental illness ...................29

Consequences of seeking mental health treatment $\ldots \ldots \ldots \ldots \ldots \ldots \ldots . \ldots 29$

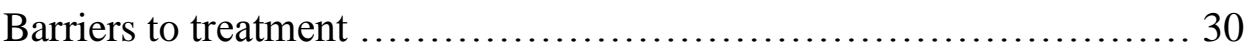

Likelihood of seeking mental health treatment ..................... 30

CHAPTER 3: Results .................................................... 32

Reported Psychological Functioning of Soldiers ......................... 32

Part 1: Stigma for Admitting the Presence of a Mental Illness ................ 33

Descriptive Data ........................................... 33

Respondents' Concerns about Stigmatizing Attitudes ................ 34

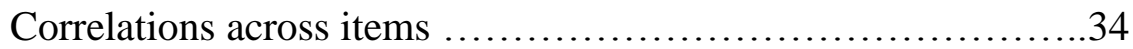

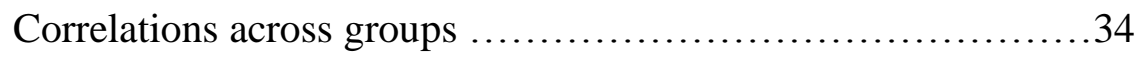

Weakness/Incompetence or Dangerousness: Which is the Greater Concern? ............................................................ 37

Military Personnel, Civilians, or Self: Who Causes Greater

Concern? ..................................................... 38

Relationship between Psychological Symptoms and Perceived

Stigma for Having a Mental Illness .............................. 40

Part 2: Stigma Associated with Seeking Treatment for a Mental Illness ........ 41

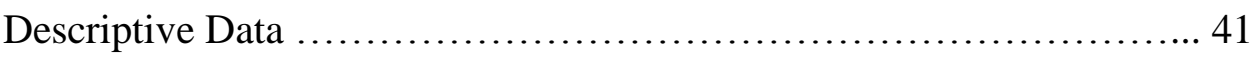

Respondents' Concerns about Stigmatizing Attitudes about Treatment-

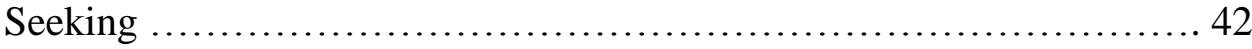


Correlations across items .................................. 42

Correlations across groups ................................... 43

Treatment Being a Bad Idea/Unhelpful or Bad for One's Military

Career: Which is the Greater Concern? ................................ 45

Military Personnel, Civilians, or Self: Who Causes Greater

Concern? ....................................................... 46

Relationship between Psychological Symptoms and Perceived

Stigma for Treatment-Seeking ..................................... 48

Part 3: Predictors of Treatment-Seeking..................................... 49

Likelihood of Treatment-Seeking at a V.A. or Non-V.A. ...............49

Stigma as a Predictor of Treatment-Seeking......................... 50

Frequencies of Reported Barriers to Treatment ....................... 51

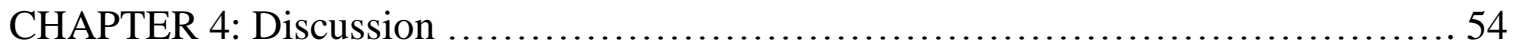

Findings with Regards to Hypotheses ..................................... 54

Concerns about being perceived as weak/incompetent versus dangerous ............................................................ 54

Differences between ratings of various target groups for stigma related to having a mental illness .................................. 55

Concerns regarding how treatment-seeking is perceived .............. 56

Differences between ratings of each target group for stigma related to

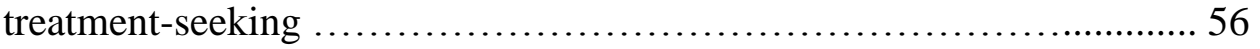

Relationship between self-stigma and public stigma ................... 56

Treatment-seeking at a V.A. facility .............................. 57

Perceived barriers to treatment ................................... 58

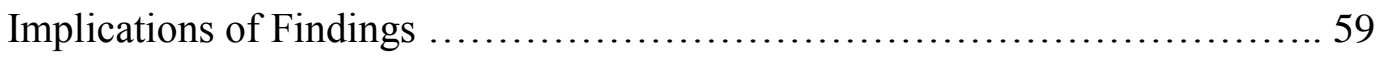

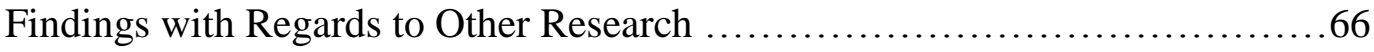




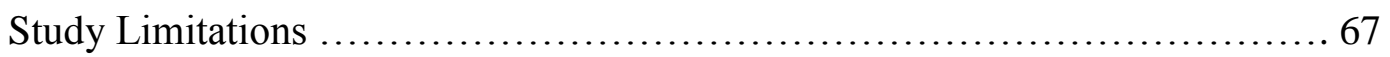

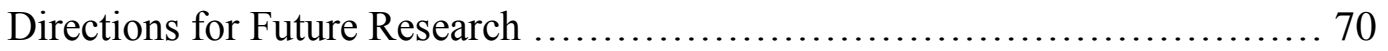

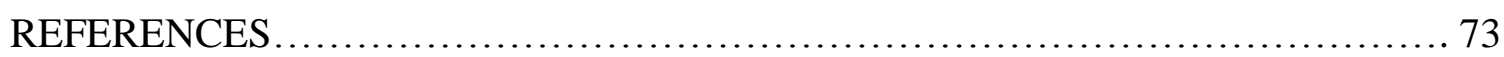

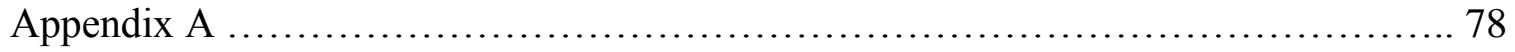

Appendix B .......................................................... 80 


\section{LIST OF TABLES}

Table 1

Means and Standard Deviations for Stigma Items Related to Having a Mental

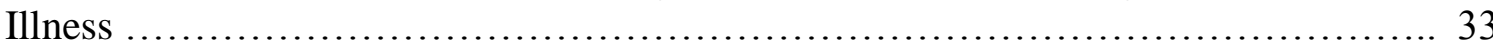

Table 2

Correlations between Individual Stigma Items Related to Having a Mental Illness .... 34

Table 3

Correlations between Groups for Stigma Ratings for Having a Mental Illness .......... 36

Table 4

Mean Scores for Self, Civilian Others, and Military Others for Stigma Related to

Having a Mental Illness ....................................................... 37

Table 5

Comparisons between Respondents' Ratings of Military and Civilian Others of Stigma for Having a Mental Illness

Table 6

Comparisons between Respondents' Ratings of Self and Military Others of Stigma

for Having a Mental Illness

Table 7

Comparisons between Respondents' Ratings of Self and Civilian Others of Stigma

for Having a Mental Illness

Table 8

Correlations between PTSD, Depression, and Perceived Stigma for Treatment-

Seeking

Table 9

Means and Standard Deviations for Treatment-Seeking Stigma Items 42

Table 10

Correlations between Individual Treatment-Seeking Stigma Items

Table 11

Correlations between Groups for Treatment-Seeking Stigma Items 44

Table 12

Mean Scores for Self, Civilian Others, and Military Others for Treatment-Seeking

Stigma Items 45 
Table 13

Comparisons between Respondents' Ratings of Military and Civilian Others of Treatment-Seeking Stigma Items

Table 14

Comparisons between Respondents' Ratings of Self and Military Others of

Treatment-Seeking Stigma Items

Table 15

Comparisons between Respondents' Ratings of Self and Civilian Others of

Treatment-Seeking Stigma Items

Table 16

Correlations between PTSD, Depression, and Perceived Stigma for Treatment-

Seeking

Table 17

Number of Soldiers Who Endorsed Each Perceived Treatment Barrier 


\section{CHAPTER 1}

\section{Introduction}

In times of war, individuals in the military have an increased risk of developing psychological symptoms due to being exposed to combat and experiencing traumatic events. Because military personnel return from deployment and have to function in either civilian or military life, exploring issues related to mental health among these men and women is crucial for their psychological well-being and quality of life. It is therefore important to examine mental illness, treatment-seeking, and barriers to treatment among veterans. This issue has become more salient in recent years. The United States commenced military operations overseas in Iraq and Afghanistan after the attacks of September 11, 2001. As of October, 2007, over 1.6 million troops had been deployed to Operation Iraqi Freedom (OIF) and Operation Enduring Freedom (OEF; Tanielian, Jaycox, Adamson, \& Metscher, 2008), and the total number is well over 2,000,000 at present.

In what follows, the presence and impact of mental illness in the military is discussed. Prevalence of various disorders among those who served in Vietnam and OIF/OEF are examined, and problems associated with mental illness among veterans are discussed. Furthermore, treatment-seeking rates and barriers to treatment for mental health problems among veterans are reviewed. The review establishes the need to understand more fully the issues related to veterans' willingness (or lack thereof) to seek treatment for mental health concerns. It is the aim of this study to clarify further the reasons some military personnel do not seek treatment for psychological problems. 


\section{Mental Illness among Military Veterans}

This section reviews studies of the rates of mental illness among military personnel exposed to combat and its associated trauma. Studies of the long-term effects of mental illness among veterans are also reviewed, as are studies of the effectiveness of treatment for veterans with mental illness.

\section{History}

Mental illness among military persons in combat has been documented in literature for centuries (e.g., the Bible, Shakespeare, "The Red Badge of Courage”). During the Civil War, theories to explain syndromes related to traumatic events were generally focused on physical explanations such as cardiovascular functioning. Terms such as "Da Costa's syndrome," "neurocirculatory asthenia," and "soldier's heart" were used to describe what is now recognized as posttraumatic stress disorder (PTSD). During World War I, theories focused more on brain disruption, and the term "shell shock" was used to describe soldiers' reactions to trauma. Psychological theories were also developing and proposed the ideas of "nostalgia," "combat fatigue," "war neurosis," and “combat exhaustion” to explain PTSD symptoms. In 1941, psychiatrist Abram Kardiner was the first to propose that soldiers' reactions to traumatic events were both physiological and psychological in nature, as he observed World War I veterans reliving their traumas with both physical and emotional responses (van der Kolk, 2010).

In 1952, following the second World War, the Diagnostic and Statistical Manual of Mental Disorders (DSM) was created by the American Psychiatric Association (APA). 
It included the term "gross stress reaction" to describe the trauma response of some previously normally-functioning individuals who were exposed to abnormally stressful circumstances, such as combat. However, the APA removed the term in the second edition of the DSM, taking with it an adequate description of the psychological responses of soldiers to war-related trauma. In the DSM-III (APA, 1980), the term "posttraumatic stress disorder" was introduced, which described an individual's reaction to a traumatic event, and included symptom categories comparable to what are used to diagnose PTSD today (Friedman, Resick, \& Keane, 2010). This revision again gave a name to a phenomenon occurring among many veterans, with symptoms being especially apparent among those who had served in the Vietnam War. The number of veterans returning to civilian life after Vietnam made their psychological symptoms and associated problems difficult to ignore.

\section{The Conflict in Vietnam}

According to the Department of Defense, almost 2.6 million military personnel served active duty in South Vietnam. Among those who were in theater, 58,220 were reported or presumed to have been killed. An additional 153,303 were wounded severely enough to require hospital care (Department of Defense, 2008). A large number of Vietnam veterans likely experienced significant stress or even traumatic events as a result of being involved in the conflict.

The National Vietnam Veterans Readjustment Study (NVVRS) was conducted in 1990 to examine rates of various mental illnesses among veterans who had served in Vietnam, individuals who had served in the military during the Vietnam War era (19641975) but did not deploy, and civilians. Respondents were randomly selected from a 
comprehensive database of military records. The researchers assessed for current and lifetime prevalence of PTSD, depression, generalized anxiety disorder, and alcohol problems. An in-depth, structured interview (Diagnostic Interview Schedule; DIS) based on the DSM criteria for various mental illnesses was completed with 3,016 participants. The groups were balanced for gender, age, and race. Data collection occurred from19861988 (Jordan et al., 1991).

The results indicated that $15.2 \%$ of male and $8.5 \%$ of female Vietnam veterans met criteria for PTSD at the time of the study (that is, 15 years after the end of the war). They also indicated that, compared to non-theatre Vietnam-era veterans, those who were in theatre in Vietnam reported significantly higher levels of depression (4.5\% versus $2.3 \%)$, generalized anxiety (4.9\% versus $3.2 \%)$, and alcohol problems (13.7\% versus 9.2\%). Not surprisingly, civilians reported fewer psychological problems compared to Vietnam veterans (Jordan et al., 1991). These findings suggest that veterans can experience mental health problems long after returning from war.

\section{Mental Illness among OIF/OEF Veterans}

Current military operations in Iraq and Afghanistan commenced following the attacks on United States soil on September 11, 2001. As of June 20, 2011, there have been 1,619 deaths among United States military serving in OEF and 4,408 deaths among those serving in OIF. Additionally, 45 deaths have been reported among those fighting in Operation New Dawn (Department of Defense, 2011), the new name given to military operations in Iraq as of September, 2010, to reflect the initiation of decreasing the presence of U.S. troops in Iraq. The Department of Defense (2011) also reported that, as of June 20, 2011, 44,266 service members have been wounded in Iraq and Afghanistan. 
Milliken, Auchterlonie, and Hoge (2007) examined rates of mental illness among soldiers returning from Iraq. Data collection occurred between June 1, 2005 and December 31, 2006, and ranged from 4-10 months post-deployment. The participants completed self-report questionnaires and interviews with clinicians, and information was collected about symptoms related to PTSD, depression, suicide, and alcohol problems, as well as other problems in functioning. The assessments were conducted with 56,350 active duty soldiers and 31,885 reserve or National Guard soldiers.

Among the active duty personnel, $16.7 \%$ screened positive for PTSD, $0.6 \%$ reported suicidal ideation, $10.3 \%$ reported depressive symptoms, $11.8 \%$ screened positive for alcohol problems, $14 \%$ reported interpersonal conflict, and 2.2\% reported aggressive ideation. Among reserve or National Guard soldiers, 24.5\% screened positive for PTSD, $1.5 \%$ reported suicidal ideation, $13.0 \%$ reported depressive symptoms, $15 \%$ screened positive for alcohol problems, $21.1 \%$ reported interpersonal conflict, and $4.0 \%$ reported aggressive ideation. These findings indicate that a substantial number of individuals who return from service in Iraq endorse symptoms consistent with having a mental illness several months after deployment.

Mental health problems among female OIF and OEF veterans were also assessed by Owens, Herrera, and Whitesell (2009). Questionnaires assessed PTSD, depression, alcohol problems, general distress, and other mental health problems. The veterans had returned from Iraq or Afghanistan an average of 22 months earlier and were in the Army, Marines, Navy, or Air Force. Twenty-four percent of the sample reported PTSD symptoms that exceeded the cutoff to meet criteria. When asked about other mental health problems, $48 \%$ reported depression, $36 \%$ reported anxiety, $66 \%$ reported 
significant alcohol use, 38\% reported relationship problems, and 30\% reported anger management problems. General distress scores were similar to norms for treatmentseeking in general. The researchers also found that $78 \%$ of the veterans reported needing mental health treatment for one or more problems.

In a study comparing rates of substance use among OIF and OEF veterans to a population-based sample, 12,072 veterans were given self-report measures assessing alcohol, tobacco, and drug use behaviors within the past month and the past year. Nonveteran controls from the National Study on Drug Use and Health (NSDUH) were used for comparison and were similar to the veterans in age, gender, and geographical location. The findings indicated that, over the previous month, veterans engaged in significantly more alcohol use (56.6\% versus $50.8 \%$ ), heavy alcohol use (defined as five or more drinks on the same occasion at least five times in the previous month; 7.5\% versus $6.5 \%)$, daily smoking ( $18.8 \%$ versus $14.3 \%)$, and marijuana use (3.5\% versus $3.0 \%$ ) compared to nonveterans. In the previous year, veterans were found to have driven under the influence of alcohol or drugs (13.2\% versus $12.2 \%)$ and obtained counseling or treatment for alcohol or illicit drug use $(0.8 \%$ versus $0.5 \%)$ at significantly higher rates compared to nonveterans (Wagner et al., 2007).

Suicide has been a specific focus among military families and those working with veterans, as military officials report that rates of suicide are alarmingly high among both veterans and those currently serving in the military (Carden, 2010). The Department of Veterans Affairs Office of Inspector General (2007) reported that 5,000 living veterans die by suicide annually. Rates of suicide have consistently increased annually since 2001 among service members across all branches of the military; in 2001, 160 suicides were 
reported among military personnel across all branches, with that rate steadily rising each year to 309 in 2009 (Department of Defense Task Force on the Prevention of Suicide by Members of the Armed Forces, 2010).

\section{Effects of Mental Illness on Veterans}

Research has evaluated how symptoms of mental illness negatively impact a veteran's life. Barrett, Green, Morris, Giles, and Croft (1996) gave 2,441 Vietnam veterans neuropsychological tests assessing verbal learning and memory, visuospatial abilities and memory, mental flexibility, and intelligence. Their findings suggested that having a diagnosis of PTSD alone was not associated with diminished performance on cognitive tests, but veterans with PTSD and another, comorbid mental illness (e.g., depression, substance disorder, generalized anxiety disorder) obtained lower scores on each measure of neuropsychological functioning.

PTSD has been linked to cognitive problems among veterans in other research as well. Veterans with PTSD have been found to perform more poorly on tests of sustained attention, learning, and working memory, as well as on intelligence subtests measuring abilities in the areas of word knowledge and general knowledge compared to veterans without PTSD (Vasterling et al., 2002; see also Samuelson et al., 2006; Schrimsher, Parker, \& Burke, 2007).

The psychological distress of PTSD has also been found to be related to physical problems among veterans. Hoge, Terhakopian, Castro, Messer, and Engel (2007) examined data from 2,863 soldiers from four infantry brigades who had returned from Iraq one year earlier. The veterans were given self-report questionnaires assessing symptoms of a range of disorders, including PTSD, and their physical functioning. 
Reports of PTSD symptoms were related to poorer self-reports of physical health, more frequent visits to sick call (to which military personnel report when illness prevents them from working), and more missed work days. PTSD symptoms were also associated with reports of lower energy levels, poorer quality of sleep, and higher rates of reported somatic symptoms. The connection between poorer physical health and PTSD was even greater when PTSD was comorbid with another disorder, such as depression or substance abuse (see also Zivin et al., 2008).

Veterans with a mental illness can experience problems in close relationships as well. For instance, depression among veterans has been found to be related to problems in family relationships (Sayers, Farrow, Ross, \& Oslin, 2009). Difficulties in romantic relationships have also been reported by veterans with trauma symptoms. Nelson Goff, Crow, Reisbig, and Hamilton (2007) administered self-report questionnaires to 45 male OIF and OEF veterans and their female spouses or partners assessing trauma symptoms, traumatic events, and relationship satisfaction. Trauma symptoms predicted lower levels of relationship satisfaction for veterans and their partners, while reports of depressive and anxiety symptoms were not linked to levels of relationship satisfaction.

Another study investigated whether symptoms of PTSD were related to suicide among 50 Vietnam veterans with a diagnosis of PTSD. The participants were given a structured interview assessing trauma symptoms, and they completed self-report measures of suicidal ideation. It was found that the specific symptom category of reexperiencing the traumatic event (e.g., in nightmares or flashbacks) was related to suicidal thoughts and behaviors (Bell \& Nye, 2007). The experience of PTSD symptoms has also been associated with increased aggression (Taft et al., 2007), depressive 
symptoms (Lapierre, Schwegler, \& LaBauve, 2007), and alcohol and drug abuse (McFall, Mackay, \& Donovan, 1992).

The functional impairment associated with psychological problems undoubtedly affects veterans in a variety of ways. The areas in which problems are reported likely exacerbate symptoms, initiating a cycle of distress and related problems. For instance, if a veteran with PTSD experiences sleep difficulties, their attention may be diminished as a result, leading to poor work performance. This could lead to loss of employment, lost wages, and increased relational problems, which may cause additional anxiety. This, in turn, may contribute to more sleep problems, possible physical effects, and additional psychological symptoms, unquestionably impacting the veteran's quality of life and overall functioning. In considering this type of chain of events, the necessity of addressing and intervening in the psychological functioning of military members seems obvious.

\section{Effectiveness of Mental Health Treatment among Veterans}

Mental health and psychological treatment of veterans has been extensively studied, and its effectiveness has improved over the years. Bolton et al. (2004) assessed pretreatment and post-treatment psychological symptoms and quality of life among veterans enrolled in group treatment focused on either psychoeducation $(n=105)$, anxiety/stress management $(n=62)$, or anger management $(n=30)$. All three types of treatment were found to be effective. The reexperiencing symptoms of PTSD significantly decreased among the veterans who completed the psychoeducational group. Among the veterans who completed the anxiety/stress management group, levels of depression significantly decreased over time, while scores of life satisfaction significantly increased. Veterans 
who completed the anger management group were found to report significantly less frequent incidents of violence and better overall health following treatment.

In other research, a group of 1,148 veterans completed cognitive-behavioral therapy. Alcohol consumption, alcohol dependence, substance abuse, depression, and anxiety were all found to decrease between the time of intake and a one-year follow-up (Ouimette, Finney, \& Moos, 1997). Furthermore, the researchers determined that the number of veterans who reported unemployment, arrests, and homelessness significantly decreased by follow-up, whereas the number of veterans who reported to be in remission or abstinent from alcohol increased.

Rauch et al. (2009) examined how prolonged exposure (PE) impacted psychological symptoms among 10 veterans at a V.A. who were diagnosed with chronic PTSD. Veterans were given pre- and post-treatment questionnaires assessing symptoms of PTSD and depression. The results indicated that these veterans reported significant reductions in symptoms of hyperarousal, reexperiencing, avoidance, and depression. Ready et al. (2008) examined the effectiveness of group-based exposure therapy (GBET) in a study involving 102 veterans at a V.A. Participants were given a structured interview and self-report measures of PTSD both before and after treatment. Participants reported significantly lower levels of PTSD symptoms after completing GBET. In fact, $81 \%$ of the veterans exhibited significant levels of improvement both immediately following treatment and six months after GBET completion.

\section{Summary}

In summary, research indicates that a considerable number of veterans have experienced or will experience a mental illness, with associated problems in physical 
health, cognitive functioning, and relationships. Fortunately, research also suggests that various types of psychological treatment (e.g., cognitive-behavioral, exposure) are effective in reducing symptoms of mental illness. Unfortunately, research suggests that a substantial treatment gap exists among veterans with a mental illness and those seeking treatment.

\section{Treatment-Seeking in the Military}

The following review examines rates of treatment-seeking among veterans, as well the barriers reported by veterans as they contemplate help-seeking or attempt to seek treatment for mental health problems.

\section{Treatment-Seeking among Veterans}

Hoge et al. (2004) administered anonymous surveys assessing mental health and utilization of services among veterans from three Army infantry units and one Marine unit. One infantry unit completed the surveys just prior to deployment to Iraq, the second completed them following a six-month deployment to Afghanistan, the third completed them following an eight-month deployment to Iraq, and the Marine unit completed them following a six-month deployment to Iraq. Those who were given the surveys following deployment completed them three to four months after returning to the United States. The researchers found that 731 soldiers met criteria for major depression, generalized anxiety disorder, or PTSD. Of these, about $73 \%$ acknowledged that they had a psychological problem, yet only about $36 \%$ reported interest in receiving treatment. Furthermore, only about $27 \%$ reported having sought treatment within the previous year, and only about $16 \%$ reported that they had actually seen a mental health professional. In other words, 
only about 1 in 6 veterans who met criteria for a mental illness reported that they had received treatment from a mental health professional.

Erbes, Westermeyer, Engdahl, and Johnsen (2007) examined rates of treatmentseeking among veterans. Self-report questionnaires were administered to 240 OIF and OEF veterans enrolled for care at the Veterans Affairs (V.A.) Hospital in Minneapolis. Of the 240 contacted, 120 completed questionnaires assessing mental illness and utilization of mental health treatment before, during, or up to six months after deployment. The researchers determined that mental health services in the forms of individual therapy, group therapy, and/or medication was reportedly sought by $56 \%$ of the sample. However, these results might be limited in terms of their application. First, the participants in the study by Erbes et al. were already enrolled for care at the V.A. (i.e., engaging in helpseeking behaviors), suggesting that the sample may not be representative of most veterans. In addition, Erbes et al., the researchers categorized required military debriefings as a form of mental health service.

In other research assessing rates of treatment-seeking in the military, Hoge, Auchterlonie, and Milliken (2006) examined information from the military health records of 222,620 service members who served in OIF and 16,318 service members who served in OEF. They examined whether each individual sought mental health treatment within one year of returning from deployment. Mental health treatment was identified by a primary diagnosis of a mental disorder based on the International Classification of Diseases, Ninth Revision, Clinical Modification (ICD-9-CM) and type of service sought (i.e., psychiatry, psychology, social work, alcohol or substance abuse treatment, or treatment at a multi-disciplinary community mental health clinic). The researchers found 
that, among those with a mental illness, $31 \%$ of those who served in OIF had been seen in a mental health outpatient setting within their first year home, whereas the rate among those who served in OEF was 19.5\% (Hoge et al., 2006). The lower rates for OEF service members may be explained by the fact that those who had deployed to OIF had typically engaged in more combat in the earlier stages of the conflicts (Hoge et al., 2004). The study also found that 9,611 OIF service members were referred for mental health treatment through the post-deployment health assessment process, but only $56.3 \%$ of those referred were found to have sought treatment within their first year home. For OEF service members, the rate of follow-through for referrals to mental health services was 48.2\% (Hoge et al., 2006). These numbers suggest that only a small portion of veterans who sought help did so through a referral for mental health treatment by the military, and only about half who were referred actually sought treatment. It is unknown whether veterans of these wars sought treatment from private facilities, as this information would not be in veterans' military records unless self-disclosed.

Cully et al. (2008) examined rates of treatment-seeking among veterans as well. In their study, information from the V.A. records of 410,923 veterans who were documented to have been diagnosed with depression, anxiety, or PTSD between October, 2003 and September, 2004 was collected to determine whether the veterans had sought psychotherapy within 12 months of being diagnosed. Veterans from all eras were included, and the average age was about 59 years. The results showed that only $22 \%$ of the veterans had received at least one session of psychotherapy within a year of being diagnosed with depression, anxiety, or PTSD. In other words, approximately 4 out of 5 veterans with one of these disorders went untreated in the year following their diagnosis. 


\section{Barriers to Seeking Treatment among Veterans}

It may be that many veterans recognize that they have a mental health problem and would like to seek treatment, but that they experience barriers that discourage or prevent them from doing so. Barriers to mental health care can be external (e.g., environmental barriers, such as transportation problems or financial cost) or personal (e.g., fear of being stigmatized).

External barriers. Hoge et al. (2004) asked 731 veterans who met screening criteria for a mental illness to identify barriers they perceived to mental health treatment. Getting time off work was reported as a barrier by $55 \%$ of the veterans, while $45 \%$ reported difficulty making an appointment, $25 \%$ reported that mental health care is too expensive, and $18 \%$ reported difficulty with transportation for treatment. Stecker, Fortney, Hamilton, and Ajzen (2007) also found that 7 out of 20 National Guard soldiers who met criteria for a mental illness identified difficulty getting time off work as a barrier to treatment.

Personal barriers. Even more relevant to military personnel may be personal barriers to care. For example, Hoge et al. (2004) found that $38 \%$ of the veterans in their sample reported a lack of trust in mental health professionals as a barrier; while $25 \%$ indicated a belief that mental health care does not work.

Stigma can impact the treatment-seeking process and has been associated with avoidance of treatment. Stigma has been defined as "negative and erroneous beliefs" about a person with a mental illness (Corrigan \& Penn, 1999). Corrigan and Kleinlein (2005) distinguished between self-stigma and public stigma. With self-stigma, individuals with a mental illness hold negative beliefs about themselves (e.g., "If I have a 
mental illness, I must be incompetent"). Public stigma, on the other hand, involves the negative beliefs held by the general public about people with mental illness (e.g., "People with a mental illness are dangerous”). Furthermore, Corrigan (2004) stated that public stigma can lead to self-stigma because individuals with a mental illness may internalize views they perceive others to have about people with a mental illness. He suggested that people may avoid labeling themselves as mentally ill and avoid seeking treatment to keep from feeling negatively about themselves. Both types of stigma are likely active in the military. Moreover, for all persons but perhaps for military personnel in particular, public stigma and self-stigma likely influence each other.

Self-stigma in the military. Self-stigma may prevent military personnel from admitting a mental illness because having a mental illness likely conflicts with veterans' self-perceptions. Nash (2007) suggested that service members typically view themselves as strong and competent; therefore, experiencing psychological symptoms may be viewed as weak and accompanied with shame. Furthermore, Nash stated that feelings of shame are intensified because soldiers and Marines are trained to handle combat and are aware of the risks they may encounter when voluntarily signing up for the military. If veterans are trained to view themselves as strong and competent, then the self-stigma (e.g., I am weak if I have a mental illness) related to admitting a problem may prevent them from recognizing a mental illness or from seeking treatment.

Public stigma in the military. Concerns about admitting a mental health problem to others has been found among members of the military. Britt (2000) compared veterans' attitudes towards seeking treatment for a medical problem with those for seeking treatment for a psychological problem. In two studies using self-report questionnaires, 
veterans returning from military operations in Bosnia were asked about their physical and psychological health and about seeking treatment for physical and psychological problems. In the first study, participants $(n=708)$ were asked about their concerns of stigmatization in answering psychological versus medical questions, their level of comfort when reporting physical and psychological symptoms, and their likelihood of following through with a psychological versus medical referral. In the second study, soldiers $(\mathrm{n}=531)$ indicated the level of stigma that they would perceive if they admitted a psychological problem versus a medical problem by reporting how others would view and treat them. The results indicated that soldiers felt significantly less comfortable discussing a psychological problem compared to a medical problem and were less likely to follow through with a psychological referral compared to a medical referral. Moreover, the participants reported significantly higher levels of perceived public stigma associated with admitting a psychological problem compared to admitting a medical problem. Specifically, results indicated that $61 \%$ of respondents reported that they would be concerned that admitting a psychological problem would be detrimental to their military careers, while only $43 \%$ reported this concern related to admitting a medical problem. Furthermore, $45 \%$ reported concern that military coworkers would spend less time around them if they admitted a psychological problem, while only $22 \%$ reported this concern related to a medical problem (Britt, 2000).

Britt (2000) argued that the way the post-deployment screening process for mental health problems is organized may not facilitate accurate responding to questions about psychological functioning. When military units undergo screening after deployment, individuals often stand in line together and can thereby see when peers are 
referred to a medical doctor or a psychologist because designated waiting areas are within view. This type of situation compromises privacy for veterans and, perhaps, their willingness to admit a need for help. Indeed, Britt noted that veterans were heard making comments about peers who were referred for psychological follow-up such as, "Should I take his weapon?" If this type of behavior is observed in the context of military mental health screening, it is not surprising that public stigma may be a concern among veterans who are experiencing mental illness. Such stigma would encourage veterans to minimize symptoms and not obtain the treatment they may need.

In another study (Porter \& Johnson, 1994), 252 Navy and Marine service members were sent self-report surveys to evaluate their views towards other members of the military who seek treatment for a mental illness. The participants were given scenarios in which military personnel had received or were continuing to receive mental health treatment in one of several forms (e.g., outpatient therapy, alcohol treatment, psychiatric hospitalization, mental health evaluation). They were asked to rate the individual in the scenario on a number of factors, including reliability and competency. Additionally, the participants were asked to indicate how having a mental illness should affect a subordinate in the military, including whether a commanding officer should be made aware of psychiatric treatment history and whether mental health treatment history should be a factor when considering whether a subordinate should be promoted. The surveys were returned by 138 officers who were either in the U.S. or deployed. The results indicated that respondents viewed subordinates who have sought mental health treatment as competent and somewhat reliable. Moreover, responses indicated a neutral view of superior officers who sought mental health treatment. The findings also showed 
that responders thought that past mental health treatment should not be a factor when considering whether an individual should be promoted. An additional finding was that participants believed officers should be told what mental health services subordinates have sought and the reason for seeking treatment (Porter \& Johnson, 1994).

These findings indicate that military officers generally do not tend to subscribe to a negative view of those who seek treatment for a mental illness. It does suggest, however, that they feel they should be aware of the mental health history of their subordinates (Porter \& Johnson, 1994). Because these findings were contrary to what was predicted, it is important to assess why the researchers obtained these results. First, study participants were all higher-ranking officers. Subordinates who might be considering seeking treatment for a mental health problem may be more concerned about how they will be viewed by their peers rather than their superiors. For instance, if soldiers view their peers with a mental illness as dangerous or incompetent, they may feel concern about accompanying them on missions or view them as a weak part of the unit, which may affect how they treat the individual. Superiors also may be more educated about mental illness because of training required to be higher-ranking, which may result in attitudes towards individuals with a mental illness that are less negative. Moreover, superiors may feel pressure to respond in a way that portrays themselves as open and accepting, which may have affected the results. Furthermore, the questions in this study were aimed at determining how officers viewed individuals who were already seeking help for a mental illness (Porter \& Johnson, 1994). However, officers may view someone who is already receiving treatment or who has already completed treatment differently than an individual who has a mental illness but has not received treatment because the 
individual who has not had treatment likely still experiences symptoms. Finally, it should be noted that it is unclear who completed the surveys. No information is provided regarding the percentage of Naval officers versus Marine officers who responded (Porter \& Johnson, 1994). There may be differences in how each branch of the military treats mental illness and how much each branch is exposed to issues related to mental illness. Additionally, Porter and Johnson cited deployment as a reason that many of the surveys were not returned. Service members who experience deployment and have encountered more situations involving trauma may have differing views of mental health than those who have not been deployed.

Other research indicates that military personnel identify public stigma as a barrier to treatment. Concerns of public stigma related to treatment-seeking were examined by Hoge et al. (2004). They reported that the three most frequently reported reasons for not seeking treatment included concerns of being viewed by others as weak (reported by $65 \%)$, being treated differently by unit leaders (63\%), and having other unit members feel less confident in them (59\%). Other veterans reported that seeking treatment would be too embarrassing (41\%) and that it would be harmful to their career (50\%). Warner, Appenzeller, Mullen, Warner, and Grieger (2008) administered self-report surveys to 2,678 soldiers returning from deployment to investigate beliefs about barriers to treatment. The researchers found that soldiers expressed concern about unit members having less confidence in them, unit leaders treating them differently, seeking treatment being harmful to one's career, seeking treatment being too embarrassing, being seen by others as weak, and evidence of mental health care in the medical record being harmful to one's career. 
Warner et al. (2008) also asked participants to identify how barriers to mental health treatment could be overcome. The responses indicated that a substantial number of veterans identified factors that would facilitate overcoming barriers. These factors included: encouragement from family and friends; unit leaders expressing that treatmentseeking would not harm careers; direct supervisors indicating the importance of seeking care; getting time off work without negative consequences; getting after-hour care to prevent one's unit from knowing about one's treatment-seeking; additional education to inform veterans whether they have problems; and being certain that one's command would be unable to find out the details of one's problems. These responses lend additional support to research indicating that veterans often do not seek mental health treatment because of concern of public stigma.

Not all veterans report experiencing concern about others' perceptions of them if they admit or seek treatment for a mental illness. Stecker et al. (2007) interviewed 20 Army National Guard soldiers with a mental illness about their treatment-seeking beliefs. The majority of the veterans (15 out of 20 ) reported that others, including those in the military, would be supportive if they decided to seek treatment. One participant reported that "the only people [he has] to answer to are God and [his] wife" (p. 1360) and that he has nobody else that can make him feel that he is "in trouble" if he decides to seek treatment. Another veteran compared seeking treatment from a mental health professional to seeing a dentist for a toothache and stated that stigma is not a concern. The remaining 5 out of the 20 veterans reported that their family members would rather they "suck it up' and not identify themselves as needing help" (p. 1360). It is important to consider that this study utilized a small sample size, and the participants were in the National 
Guard. It may be the case that active duty veterans who are consistently surrounded by the military culture may view mental illness and stigma differently than those who are in the National Guard or reserves and are likely to spend less time in the military context.

The association between self-stigma and public stigma. Research has established that there is an association between the two types of stigma (e.g., Corrigan \& Watson, 2002), and this may be particularly true for military personnel. GreenShortridge, Britt, and Castro (2007) suggested that, when a soldier experiences a traumatic event and later develop PTSD symptoms, the individual may outwardly exhibit symptoms observed by others. Public stigma may result in that other members of the military may view the person in a negative way and treat him or her differently. The individual may then internalize the public stigma and engage in self-stigmatization. Selfstigma, the authors suggested, can decrease one's likelihood of seeking mental health treatment because of lowered ambition resulting from lower self-esteem. Furthermore, they stated that members of the military with a mental illness may feel that they should be able to control their symptoms, which can lead to the choice to avoid seeking treatment.

\section{Summary}

Regardless of which estimates of treatment-seeking behavior is used, it is apparent that there are considerable numbers of veterans or military personnel that may be experiencing symptoms of a mental illness but are not being treated. Those who have an untreated mental illness may also exhibit impaired functioning in their occupational, relational, educational, and/or physical health, likely diminishing their overall quality of life. Veterans of past and present conflicts have been shown to report psychological symptoms with substantial prevalence, even years after returning from service overseas. 
This treatment gap between those who need psychological services and those who obtain services is necessary to address. While some barriers to treatment, including stigma, have been investigated, further examination of why many veterans choose not to seek mental health treatment is important to understand.

\section{The Present Study}

Research on mental illness and its treatment in the military has been limited by several factors. First, studies with veterans have typically focused less on self-stigma and more on public stigma. The views that military service members may hold of themselves with regards to concerns of mental illness have been largely ignored. In addition, studies have tended to focus on public stigma related to military careers and colleagues, and they often exclude assessment of public stigma with regard to family and friends. Finally, studies on stigma in the military often fail to distinguish between stigma concerns related to admitting the presence of a mental illness versus seeking mental health treatment. The current study attempts to address these limitations.

The current study examines both self-stigma and public stigma among military personnel. Furthermore, stigma associated with both recognizing the presence of a mental illness and, separately, deciding to seek mental health treatment was examined. It examines how stigma concerns are related to the self-reported likelihood that the individual will seek mental health treatment. The study also investigates how military personnel perceive the attitudes about mental illness and treatment-seeking of others who are either in the military or who are civilians, to understand more clearly whether soldiers perceive public stigma from military others and civilian others differently. Finally, the study examines barriers to treatment-seeking in both a V.A. and non-V.A. setting. This 
study will examine whether soldiers' willingness to seek treatment differs with regards to each type of facility.

This is an exploratory study, but there are several hypotheses that are generated from the available research. The first set of hypotheses concerns stigma related to having a mental illness. It is hypothesized that, regarding admitting a mental health problem, respondents will report more concern about being perceived by military others as weak than being perceived as incompetent or dangerous because of the emphasis among soldiers to be strong. It is also hypothesized that respondents will predict more selfstigma related to being weak than being dangerous due to the emphasis within the military on strength. Additionally, it is hypothesized that perceived stigma from self and military others will be greater than perceived stigma from civilian others. This is due to the fact that the respondents were immersed in the military culture, which was likely to emphasize strength and toughness, during the previous year while deployed.

The next set of hypotheses is related to stigma for seeking treatment for a mental illness. It is hypothesized that, for respondents' ratings of self and military others, soldiers will report higher perceived stigma related to treatment being bad for one's military career or a bad idea in general compared to treatment being unhelpful. It is also hypothesized that respondents will perceive more self-stigma and stigma from military others related to the treatment-seeking process being bad for one's military career compared to perceived stigma from civilian others, as civilians are less likely to be aware of how having a mental illness might impact a soldier's military career.

The next set of hypotheses concerns aspects of the treatment-seeking process. It is hypothesized that soldiers will report a higher likelihood of seeking treatment at a non- 
V.A. facility because there may be fewer concerns about military personnel obtaining information about them related to their psychological health, since these are nongovernment agencies. It is also hypothesized that reported perceived stigma for admitting a mental illness and for seeking psychological treatment will be related to a lower level of willingness to seek treatment at either a V.A. or a non-V.A. facility. Furthermore, it is hypothesized that endorsement of PTSD symptoms will be related to a lower reported likelihood of seeking treatment. This is because, with better psychological health, soldiers are not likely to be in a position where they are actually concerned about being stigmatized for having a mental illness or seeking treatment. This lesser concern about being stigmatized is likely to be associated with an increased reported willingness to admit or seek treatment for a psychological problem.

Frequencies of reported barriers will also be examined through exploratory analyses. No hypotheses are made about these reports, but the information is important to increase understanding about what may prevent soldiers from accessing treatment in addition to concerns about stigma. 


\section{CHAPTER 2}

\section{Method}

The present study took place as part of a longitudinal study being conducted with soldiers in Fort McCoy, Wisconsin. The longitudinal study examines pre- and postdeployment factors among soldiers deployed to Iraq and how these factors may impact functioning (both physical and psychological) after returning from deployment. The longitudinal study aims to identify risk factors related to poorer physical and mental health in order to improve intervention among soldiers. The initial phase of data collection occurred in December, 2008, prior to the soldiers' deployment to Iraq. The present study utilized data collected at a second time point, in January, 2010, immediately after the soldiers' return from service in Iraq.

\section{Study Site}

Participants were active duty Army National Guard soldiers at Fort McCoy, Wisconsin who returned within the previous 1-3 days from OIF deployment. The soldiers were participating in outprocessing procedures required for all military personnel returning from deployment to Iraq. The outprocessing procedures are used by the military to provide pertinent information to the soldiers after returning from deployment, prior to being released back to their civilian lives. The procedures involve groups of soldiers listening to several hours of briefings on topics such as insurance and other benefits available to them, the process of filing claims, and mental health and alcohol awareness. Additionally, during outprocessing, the soldiers are able to meet with providers from 
local V.A. facilities to enroll for care in order to initiate treatment such as dental care or other health care.

\section{Participants}

In January, 2010, soldiers returned to Fort McCoy over a period of approximately two weeks, in groups estimated to be 180-300 in size. Data collection occurred across nine of those days. Of the approximately 2,800 soldiers processed at Fort McCoy over the two week period, an estimated 2,000 soldiers were approached to participate. A total of 761 soldiers returned completed or partially completed surveys. Of these, 14 packets were found to have questionable survey responses (e.g., inconsistent responses to similar questions, answers being selected to form visual patterns on the page). Therefore, a total of 747 soldiers' surveys were judged to be valid with regard to answers and were included in the study.

Participants included 671 males and 76 females, with ages ranging from 19-57 years $(M=28.22, S D=7.76)$. The racial background of the sample was $87.7 \%$ Caucasian, 3.9\% Latino, 2.7\% African American, and 1.7\% Asian American, with 3.9\% indicating "Other" as their racial background and $0.1 \%$ not providing racial information. Of the 745 soldiers that provided their level of education, $0.5 \%$ had not completed high school, 71.2\% had completed high school, 12.3\% had obtained an Associate's degree, 13.4\% had received a Bachelor's degree, and 2.3\% had attained a Master's degree. Soldiers of any rank were welcome to participate. However, in order to encourage the soldiers to believe that the information being gathered was anonymous, information on the soldiers' military rank was not collected. 


\section{Procedure}

Soldiers were approached in large groups after they had been exposed to one of several mental health briefings. After the briefing and before the soldiers were provided lunch, a researcher (who was not part of the prior briefing) addressed the soldiers from the podium and asked them to complete some research questionnaires while they ate. Prior to distributing the surveys, researchers gave a brief introduction and informed the soldiers that the surveys were assessing aspects of mental health among members of the military, that the responses were anonymous, and that participation was voluntary. The soldiers were also informed that those who completed the surveys would be entered into a random drawing to win one of three $\$ 100$ prizes for participating. Surveys were passed out to all soldiers, and they were instructed to turn in their completed packets to a researcher when finished. If they chose not to participate, they were asked to simply return their blank survey packet.

\section{Measures}

The packet included a cover letter that indicated the purpose of the study and contact information for the principal investigator. There was also space where soldiers could indicate whether they would like an immediate psychological evaluation by a psychologist who was on-site and available for contact during data collection.

Additionally, space was provided for soldiers to provide their name and the last four digits of their social security number. The participants were informed that providing this personal information was not required if they would like to remain anonymous and that the purpose of gathering this information was to match their surveys with other data 
points because of the longitudinal nature of the research. Participants were also told that their responses on the survey, whether they chose to provide their name or not, were completely confidential.

The survey packet included questionnaires asking for demographic information, including gender, age, racial background, relationship status, employment status, and level of education. The packet also included questionnaires about past psychological symptoms, diagnoses, and treatment, current psychological symptoms and treatment, and experiences and concerns related to deployment. For this study, a questionnaire asking about the respondent's views of mental illness and treatment-seeking, including questions about self- and public stigma and possible barriers to treatment, was developed.

PTSD Checklist- Civilian Version (PCL-C). The PCL-C is a 17-item self-report questionnaire designed to assess presence and severity of symptoms related to PTSD. The first five items address reexperiencing symptoms of PTSD, the next seven items pertain to avoidance or emotional numbing, and the last five items ask about hyperarousal. The measure asks the respondent to indicate whether each symptom has been bothering him or her for the past month by marking one of five boxes $(1=$ Not at all, $2=\mathrm{A}$ little bit, $3=$ Moderately, $4=$ Quite a bit, and $5=$ Extremely). Scores of 3 or more for each item are considered symptomatic. Internal consistency of the measure was found to be .97 among Vietnam combat veterans. The measure has also been found to be highly correlated with other measures of PTSD, such as the Mississippi Scale (.93), the PK scale of the MMPI (.77), and the Impact of Event Scale (.90; Weathers, Litz, Herman, Huska, \& Keane, 1993). 
Consequences of acknowledging a mental illness. A questionnaire was created to evaluate soldiers' opinions regarding the likely consequences, both positive and negative, of admitting that they had a mental illness (see Appendix A). It was designed to determine whether stigma may impact a soldier's likelihood of admitting a mental illness. Self-stigma was assessed using three items asking soldiers to indicate how they would view themselves if they thought they had a mental illness. They were instructed to respond to the phrase, "If I had a mental illness, I would view myself as..." "Strong," “Competent or Capable," and "Dangerous." They endorsed each item using a 4-point Likert scale ( 1 = Strongly Agree, 2 = Agree, 3 = Disagree, $4=$ Strongly Disagree). Public stigma was assessed using the same 4-point Likert scale. Soldiers were also asked to imagine that they had a mental illness and to indicate whether they would be viewed as "Strong," "Competent or Capable," and "Dangerous" by "Military superiors," "Military peers," "Military subordinates (if applicable)," "Family of origin (parents, siblings)," "Non-military friends," and "Spouse/romantic partner (if applicable)." Scores for the Dangerous item were reversed so that low scores across each question indicate a low level of concern about stigma. In the present study, the internal consistency (Cronbach's alpha) for this questionnaire was .85 .

Consequences of seeking mental health treatment. Stigma associated with seeking mental health treatment was also evaluated in a questionnaire developed for this study (see Appendix A). To evaluate self-stigma soldiers were instructed to respond to an item which stated, "If I were to seek professional treatment for a mental illness (for example, from a psychiatrist, psychologist, counselor, therapist, etc.)..." it would be "A good idea," "Helpful," and "Bad for my military career." They again used a 4-point 
Likert scale $(1=$ Strongly Agree, 2 = Agree, $3=$ Disagree, $4=$ Strongly Disagree $)$. To evaluate public stigma, they were asked to indicate, using the same scale and items, how "Military superiors," "Military peers," "Military subordinates (if applicable)," "Family of origin (parents, siblings)," "Non-military friends," and "Spouse/romantic partner (if applicable)" would view the soldier's treatment-seeking. Internal consistency (Cronbach's alpha) for this questionnaire was .90 in the present study.

Barriers to treatment. A questionnaire was also developed to evaluate perceived barriers to treatment (see Appendix B). The soldiers were asked to check a box for any or all perceived barriers to seeking treatment at either a V.A. or a non-government facility. The barriers assessed for each type of facility included "The financial cost of treatment," "Transportation problems," "Not understanding what treatment involves," "Time constraints (getting off of work, limited hours)," and "Not knowing where to go." Each item was scored as either a 0 or 1 , depending on whether the item was endorsed as a barrier $(0=$ Not endorsed as a barrier, $1=$ Endorsed as a barrier $)$.

Likelihood of seeking mental health treatment. To assess the likelihood that the respondent would seek treatment for a mental health problem, two separate questions were created for this study and included in the packet. First, the likelihood of seeking treatment at a V.A. was assessed by asking participants, "If you or your family members have concerns about your mental health, how likely are you to seek mental health services at a V.A. Medical Center or a V.A.-Community Based Outreach Center?” To measure the likelihood of seeking treatment at a non-V.A. facility, participants were asked, "If you or your family members have concerns about your mental health, how likely are you to seek mental health services at a community based (non-V.A.) center?" 
For each of these questions, the participants were asked to circle one answer on a scale of 1-5 (1 = Very Likely, 2 = Somewhat Likely, 3 = Undecided, $4=$ Somewhat Unlikely, 5 = Very Unlikely). 


\section{CHAPTER 3}

\section{Results}

The results section is presented below and is divided into three subsections, subsequent to a brief description of the participants with regards to psychological functioning. The first subsection will focus on findings pertaining to concerns about stigma for admitting the presence of a mental illness. The second subsection will present findings related to concerns about stigma for seeking treatment for a mental illness. In the third subsection, findings related to soldiers' likelihood of treatment-seeking are discussed.

\section{Reported Psychological Functioning of Soldiers}

On the PCL-C, mean substitution was used for soldiers who missed one item. It was found that 58 out of 747 soldiers $(7.8 \%)$ obtained a total score of 50 or above, which is considered to be consistent with a diagnosis of PTSD. This rate is lower than what other studies have found (e.g., Milliken et al., 2007; Owens et al., 2009); however, this may be related to the timing of the assessment, as problems may be more likely to emerge after more time has passed since returning from deployment.

When asked about depressive symptoms, 526 soldiers (70.4\%) indicated that they were experiencing minimal or no depression, 85 (11.4\%) reported symptoms consistent with mild depression, $114(15.3 \%)$ reported symptoms consistent with moderate depression, and 22 (2.9\%) reported symptoms consistent with severe depression. Because of the wide range of prevalence rates found in past research of depression among soldiers returning from OIF/OEF (e.g., Milliken et al., 2007; Owens et al., 2009), the finding that 
$29.6 \%$ of this sample reported experiencing depression is consistent with results of other studies.

\section{Part 1: Stigma for Admitting the Presence of a Mental Illness}

\section{Descriptive Data}

Table 1 shows average scores for each item on the questionnaire assessing respondents' ratings of the attitudes of self, civilian others, and military others for stigma related to admitting a mental illness. Some item labels were changed from being positive to negative so that each item reflects stigma (e.g., "Weak" rather than "Strong").

Table 1

Means and Standard Deviations for Stigma Items Related to Having a Mental Illness I would be viewed as...

\begin{tabular}{lccc} 
Target: & Weak & Incompetent & Dangerous \\
\cline { 2 - 4 } Self & $1.84(0.79)$ & $1.81(0.75)$ & $1.85(0.89)$ \\
Civilian Others & & & \\
Family & $1.67(0.70)$ & $1.69(0.71)$ & $1.73(0.85)$ \\
$\quad$ Friends & $1.81(0.75)$ & $1.82(0.74)$ & $1.94(0.92)$ \\
$\quad$ Spouse & $1.61(0.69)$ & $1.64(0.70)$ & $1.75(0.89)$
\end{tabular}

Military Others

$\begin{array}{llll}\text { Superiors } & 1.97(0.82) & 1.97(0.79) & 1.88(0.91) \\ \text { Peers } & 1.98(0.82) & 1.97(0.80) & 1.86(0.88) \\ \text { Subordinates } & 1.93(0.84) & 1.97(0.82) & 1.88(0.89)\end{array}$

Note. Lower scores indicate lower levels of stigma concern (with scores possible from 14). 


\section{Respondents' Concerns about Stigmatizing Attitudes}

Correlations across items. Correlations were calculated between respondents' ratings across all others (both military and civilian) and self on the variables Weak, Incompetent, and Dangerous. Correlation values are presented in Table 2.

As can be seen, the items Weak and Incompetent were very highly correlated. For subsequent analyses, these items were combined into one variable (by calculating their mean score). The new variable was called Weak/Incompetent. The correlation between Weak/Incompetent and Dangerous was $-0.35(p<.001)$.

Table 2

Correlations between Individual Stigma Items Related to Having a Mental Illness

\begin{tabular}{lcc}
\hline & \multicolumn{2}{c}{ Stigma Item } \\
Stigma Item: & Weak & Incompetent \\
\cline { 2 - 3 } Incompetent & $0.91^{*}$ & -- \\
Dangerous & $-0.35^{*}$ & $-0.35^{*}$ \\
\hline$* p<.001$ & &
\end{tabular}

Correlations across groups. Correlations were also calculated to determine how correlated responses were for ratings of the attitudes of self, civilian others (family, friends, spouse), and military others (superiors, peers, subordinates) for Weak/Incompetent and Dangerous. The correlations between respondents' ratings of the attitudes of military superiors, peers, and subordinates were moderate to high, ranging from 0.80-0.84 for Weak/Incompetent and 0.76-0.81 for Dangerous (all significant at $p$ $<.001)$. The correlations between respondents' ratings of the attitudes of the three 
categories of civilian others (family, peers, spouse) were also moderate to high, ranging from: 0.66-0.75 for Weak/Incompetent, and 0.68-0.73 for Dangerous. All correlations were significant at $p<.001$ (see Table 3). 
Table 3

Correlations between Groups for Stigma Ratings for Having a Mental Illness

\begin{tabular}{|c|c|c|c|c|c|c|}
\hline Target: & Self & Family & Friends & Spouse & Military Superiors & Military Peers \\
\hline \multicolumn{7}{|l|}{ Weak/Incompetent } \\
\hline Family & $0.69 *$ & -- & -- & -- & -- & -- \\
\hline Friends & $0.65^{*}$ & $0.75^{*}$ & -- & -- & -- & -- \\
\hline Spouse & $0.58 *$ & $0.73 *$ & $0.66^{*}$ & -- & -- & -- \\
\hline Military Superiors & $0.68 *$ & $0.65^{*}$ & $0.70 *$ & $0.60 *$ & -- & -- \\
\hline Military Peers & $0.66^{*}$ & $0.69 *$ & $0.73 *$ & $0.61 *$ & $0.82 *$ & -- \\
\hline Military Subordinates & $0.65^{*}$ & $0.69 *$ & $0.74 *$ & $0.62 *$ & $0.80 *$ & $0.84 *$ \\
\hline \multicolumn{7}{|l|}{ Dangerous } \\
\hline Family & $0.65^{*}$ & -- & -- & -- & -- & -- \\
\hline Friends & $0.63 *$ & $0.68 *$ & -- & -- & -- & -- \\
\hline Spouse & $0.67 *$ & $0.73 *$ & $0.70 *$ & -- & -- & -- \\
\hline Military Superiors & $0.69 *$ & $0.67 *$ & $0.65^{*}$ & $0.62 *$ & -- & -- \\
\hline Military Peers & $0.66^{*}$ & $0.74 *$ & $0.72 *$ & $0.64 *$ & $0.77 *$ & -- \\
\hline Military Subordinates & $0.70 *$ & $0.72 *$ & $0.72 *$ & $0.69 *$ & $0.76^{*}$ & $0.81 *$ \\
\hline
\end{tabular}

$* p<.001$ 
Because of the high correlations of the respondents' ratings of others across the military and civilian groups, in later analyses, they were each collapsed into one group; that is, military superiors, peers, and subordinates were collapsed into one group (military), whereas family, friends, and spouse were collapsed into one group (civilians).

\section{Weakness/Incompetence or Dangerousness: Which is the Greater Concern?}

Table 4 shows mean scores and standard deviations for respondents' ratings of the attitudes of self, civilian others (family, friends, spouse) and military others (superiors, peers, subordinates) for stigma related to having a mental illness. Paired t-tests were conducted to compare Weak/Incompetent and Dangerous across groups (with the alpha set at .007 after Bonferroni corrections).

Respondents rated civilian friends as viewing the admission of having a mental illness as more of an indication of dangerousness than of weakness/incompetence. Additionally, respondents reported military superiors and military peers as viewing having a mental illness as significantly more an indication of weakness/incompetence than of dangerousness. 
Table 4

Mean Scores for Self, Civilian Others, and Military Others for Stigma Related To Having a Mental Illness

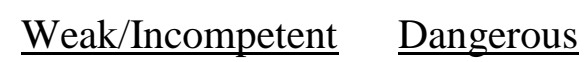

Target:

\begin{tabular}{cccc}
$\mathrm{M}(\mathrm{SD})$ & $\mathrm{M}(\mathrm{SD})$ & $t$ & $p$ \\
\hline $1.84(0.73)$ & $1.84(0.88)$ & -0.06 & .95
\end{tabular}

Civilian Others

$\begin{array}{lllll}\text { Family } & 1.69(0.68) & 1.72(0.85) & -0.90 & .37 \\ \text { Friends } & 1.83(0.73) & 1.94(0.92) & -2.87 & .004^{*} \\ \text { Spouse } & 1.64(0.68) & 1.74(0.88) & -2.33 & .02\end{array}$

Military Others

\begin{tabular}{lcccc} 
Superiors & $1.99(0.78)$ & $1.87(0.90)$ & 3.24 & $.001^{*}$ \\
Peers & $1.99(0.79)$ & $1.85(0.87)$ & 3.55 & $<.001^{*}$ \\
Subordinates & $1.97(0.81)$ & $1.87(0.88)$ & 2.29 & .02 \\
\hline
\end{tabular}

Note. Higher scores indicate greater stigma.

*Significant at $p<.007$

\section{Military Personnel, Civilians, or Self: Who Causes Greater Concern?}

Because of the moderate to high correlations found among the subcategories of military others and civilian others both before and after individual descriptor items were combined, military others and civilian others are each considered one group rather than three separate subgroups for these analyses. Scores for each group (military others, civilian others) were created using the mean across the three subcategories of groups.

Two Repeated Measures ANOVAs were conducted to determine whether there were differences among respondents' ratings of the attitudes for self, military others, or 
civilian others for Weak/Incompetent and Dangerous. These analyses revealed a significant multivariate main effect for target (that is, self, military others, or civilian others) for Weak/Incompetent, Wilks' $\lambda=.773, F(2,610)=89.80, p<.001$, partial eta squared $=.227$ and for Dangerous, Wilks' $\lambda=.984, F(2,619)=4.81, p<.001$, partial eta squared $=.016$.

Paired t-tests were then conducted to determine which target (self, military others, or civilian others) was perceived by respondents as differing from the others in their attitudes for Weak/Incompetent and Dangerous. It was found that respondents perceived more stigma from military others than from civilian others for both Weak/Incompetent and Dangerous. Results are presented in Table 5.

Table 5

Comparisons between Respondents' Ratings of Military and Civilian Others of Stigma for Having a Mental Illness

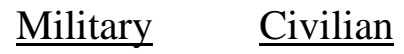

\begin{tabular}{lcccc} 
Stigma Item: & $\mathrm{M}(\mathrm{SD})$ & $\mathrm{M}(\mathrm{SD})$ & $t$ & $p$ \\
\cline { 2 - 5 } Weak/Incompetent & $1.99(0.74)$ & $1.73(0.63)$ & -13.73 & $<.001$ \\
Dangerous & $1.87(0.82)$ & $1.81(0.79)$ & -3.09 & .002 \\
\hline
\end{tabular}

Note. Bonferroni correction requires a $p$ value of .025 or less to be considered significant.

It was also found that respondents reported significantly higher perceived stigma from military others compared to self-stigma on reports of Weak/Incompetent (see Table 6 for results and for means and standard deviations). Additionally, respondents indicated significantly higher self-stigma compared to perceived stigma from civilian others for Weak/Incompetent (see Table 7 for results and for means and standard deviations). 
Table 6

Comparisons between Respondents' Ratings of Self and Military Others of Stigma for Having a Mental Illness

\begin{tabular}{lcccc}
\hline & $\underline{\text { Self }}$ & $\underline{\text { Military }}$ & & \\
Stigma Item: & $\mathrm{M}(\mathrm{SD})$ & $\mathrm{M}(\mathrm{SD})$ & $t$ & $p$ \\
\cline { 2 - 5 } Weak/Incompetent & $1.84(0.73)$ & $1.99(0.74)$ & 6.38 & $<0.001$ \\
Dangerous & $1.84(0.88)$ & $1.87(0.82)$ & 1.09 & 0.28 \\
\hline
\end{tabular}

Note. Bonferroni correction requires a $p$ value of .025 or less to be considered significant.

Table 7

Comparisons between Respondents' Ratings of Self and Civilian Others of Stigma for Having a Mental Illness

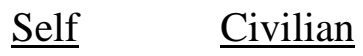

\begin{tabular}{lcccc} 
Stigma Item: & $\mathrm{M}(\mathrm{SD})$ & $\mathrm{M}(\mathrm{SD})$ & $t$ & $p$ \\
\cline { 2 - 5 } Weak/Incompetent & $1.84(0.73)$ & $1.73(0.63)$ & -5.19 & $<0.001$ \\
Dangerous & $1.84(0.88)$ & $1.81(0.79)$ & -1.07 & 0.29
\end{tabular}

Note. Bonferroni correction requires a $p$ value of .025 or less to be considered significant.

\section{Relationship between Psychological Symptoms and Perceived Stigma for Having a Mental Illness}

Correlations were run to determine whether reports of mental health problems, specifically symptoms of depression and PTSD, were related to reported perceived stigma for having a mental illness. It was found that symptoms of both depression and PTSD were significantly associated with reports of perceived stigma for self, civilian others, and military others (see Table 8). 
Table 8

Correlations between PTSD, Depression, and Perceived Stigma for Treatment-Seeking

\begin{tabular}{lll}
\hline Stigma Item: & PTSD & Depression \\
\cline { 2 - 3 } Self & & \\
Weak/Incompetent & $.10^{*}$ & $.20^{* * *}$ \\
Dangerous & $.11^{* *}$ & $.16^{* * *}$ \\
Civilian Others & & \\
Weak/Incompetent & $.17^{* * *}$ & $.25^{* * *}$ \\
Dangerous & $.14^{* * *}$ & $.17^{* * *}$ \\
Military Others & & $.28^{* * *}$ \\
Weak/Incompetent & $.17^{* * * *}$ & $.15^{* * *}$ \\
Dangerous & $.11^{* * *}$ & \\
\hline$* * * p<.001, * * p<.01, * p<.05$ &
\end{tabular}

\section{Part 2: Stigma Associated with Seeking Treatment for a Mental Illness}

\section{Descriptive Data}

Table 9 shows average scores for each item on the questionnaire assessing respondents' ratings of attitudes of stigma for seeking treatment for a mental illness. Again, item labels were changed from being positive to negative so that each item reflects stigma (e.g., "Unhelpful” rather than "Helpful”). 
Table 9

Means and Standard Deviations for Treatment-Seeking Stigma Items

My seeking treatment would be viewed as...

\begin{tabular}{lccc} 
Target: & Bad Idea & Unhelpful & Bad for Career \\
\cline { 2 - 4 } Self & $1.78(0.76)$ & $1.79(0.71)$ & $1.97(0.90)$ \\
Civilian Others & & & \\
$\quad$ Family & $1.65(0.72)$ & $1.66(0.69)$ & $1.81(0.84)$ \\
$\quad$ Friends & $1.84(0.76)$ & $1.83(0.74)$ & $1.93(0.89)$ \\
$\quad$ Spouse & $1.63(0.73)$ & $1.65(0.69)$ & $1.78(0.84)$ \\
Military Others & & & \\
$\quad$ Superiors & $1.81(0.76)$ & $1.80(0.71)$ & $1.94(0.92)$ \\
$\quad$ Peers & $1.85(0.78)$ & $1.85(0.75)$ & $1.99(0.93)$ \\
$\quad$ Subordinates & $1.89(0.77)$ & $1.88(0.74)$ & $2.03(0.93)$
\end{tabular}

Note. Lower scores indicate lower levels of stigma concern (with scores possible from 1-4).

\section{Respondents' Concerns about Stigmatizing Attitudes about Treatment-Seeking}

Correlations across items. To determine whether each stigma descriptor should be analyzed separately, correlations were run between Bad Idea, Unhelpful, and Bad for Career. Correlation values are presented in Table 10. 
Table 10

Correlations between Individual Treatment-

Seeking Stigma Items

\section{Stigma Item}

\begin{tabular}{lcc} 
Stigma Item: & Bad Idea & Unhelpful \\
\cline { 2 - 3 } Unhelpful & $0.95^{*}$ & -- \\
Bad for Career & $-0.21^{*}$ & $-0.20^{*}$ \\
\hline
\end{tabular}

${ }^{*} p<.001$

Because the items "Bad Idea" and "Unhelpful" were very highly correlated, these items were combined into one variable, referred to hereafter as Bad Idea/Unhelpful. After combining these two variables, the correlation between Bad Idea/Unhelpful and Bad for Career was $-0.17(p<.001)$.

Correlations across groups. Correlations were also conducted to determine how interrelated responses were for respondents' ratings of the attitudes of military others and, separately, for civilian others for treatment-seeking. Correlations within the military subgroups (superiors, peers, subordinates) were moderate to high, with values ranging from 0.70-0.84 for Bad Idea/Unhelpful and 0.78-0.85 for Bad for Career. For respondents' ratings of the attitudes of civilian others (family, friends, spouse), correlations were moderate to high and ranged from 0.68-0.80 for Bad Idea/Unhelpful and from 0.67-0.74 for Bad for Career. Correlations were all significant at $p<.001$ (see Table 11). 
Table 11

Correlations between Groups for Treatment-Seeking Stigma Items

\begin{tabular}{|c|c|c|c|c|c|c|}
\hline Target: & Self & Family & Friends & Spouse & Military Superiors & Military Peers \\
\hline \multicolumn{7}{|l|}{ Bad Idea/Unhelpful } \\
\hline Family & $0.73^{*}$ & -- & -- & -- & -- & -- \\
\hline Friends & $0.68 *$ & $0.68 *$ & -- & -- & -- & -- \\
\hline Spouse & $0.68 *$ & $0.80 *$ & $0.76^{*}$ & -- & -- & -- \\
\hline Military Superiors & $0.66^{*}$ & $0.77 *$ & $0.69 *$ & $0.75^{*}$ & -- & -- \\
\hline Military Peers & $0.63 *$ & $0.63 *$ & $0.78 *$ & $0.70 *$ & $0.70 *$ & -- \\
\hline Military Subordinates & $0.65^{*}$ & $0.67 *$ & $0.77 *$ & $0.71 *$ & $0.75^{*}$ & $0.84 *$ \\
\hline \multicolumn{7}{|l|}{ Bad for Career } \\
\hline Family & $0.70 *$ & -- & -- & -- & -- & -- \\
\hline Friends & $0.62 *$ & $0.67 *$ & -- & -- & -- & -- \\
\hline Spouse & $0.63 *$ & $0.73 *$ & $0.74 *$ & -- & -- & -- \\
\hline Military Superiors & $0.79 *$ & $0.73 *$ & $0.64 *$ & $0.70 *$ & -- & -- \\
\hline Military Peers & $0.75^{*}$ & $0.68 *$ & $0.70 *$ & $0.71 *$ & $0.79 *$ & -- \\
\hline Military Subordinates & $0.74 *$ & $0.73 *$ & $0.72 *$ & $0.72 *$ & $0.78 *$ & $0.85^{*}$ \\
\hline
\end{tabular}

${ }^{*} p<.001$ 


\section{Treatment Being a Bad Idea/Unhelpful or Bad for One's Military Career: Which is the Greater Concern?}

Table 12 shows mean scores and standard deviations for self-stigma and public stigma items for seeking mental health treatment. Paired t-tests were conducted to compare Bad Idea/Unhelpful and Bad for Career across groups (with alpha set at .007 after Bonferroni corrections).

When reporting how seeking treatment would be viewed, respondents indicated that they, their family of origin, and their spouses would view the process as more detrimental to their military career than being a bad idea or unhelpful.

Table 12

Mean Scores for Self, Civilian Others, and Military Others for TreatmentSeeking Stigma Items

$$
\underline{\text { Bad Idea/Unhelpful }} \underline{\text { Bad for Career }}
$$

Target:

\begin{tabular}{cccc}
$\mathrm{M}(\mathrm{SD})$ & $\mathrm{M}(\mathrm{SD})$ & $t$ & $p$ \\
\hline $1.80(0.72)$ & $1.97(0.90)$ & -4.01 & $<.001^{*}$
\end{tabular}

Civilian Others

$\begin{array}{lllll}\text { Family } & 1.67(0.69) & 1.80(0.83) & -3.26 & .001^{*} \\ \text { Friends } & 1.85(0.74) & 1.93(0.88) & -1.76 & .08 \\ \text { Spouse } & 1.65(0.70) & 1.78(0.84) & -2.77 & .006^{*}\end{array}$

Military Others

\begin{tabular}{lllll} 
Superiors & $1.82(0.72)$ & $1.93(0.91)$ & -2.73 & .007 \\
Peers & $1.86(0.75)$ & $1.97(0.92)$ & -2.68 & .008 \\
Subordinates & $1.91(0.75)$ & $2.02(0.93)$ & -2.37 & .02 \\
\hline
\end{tabular}

Note. Higher scores indicate greater stigma.

*Significant at $p<.007$ 


\section{Military Personnel, Civilians, or Self: Who Causes Greater Concern?}

Because of the moderate to high correlations found among each subcategory of military others and civilian others both before and after individual descriptor items were combined, military others and civilian others are each considered one group rather than three separate subgroups for these analyses. Scores for each group (military others, civilian others) were created using the mean across the three subcategories of groups.

Two Repeated Measures ANOVAs were conducted to determine whether there were differences among respondents' ratings of the attitudes for self, military others, or civilian others for Bad Idea/Unhelpful and Bad for Career. Repeated Measures ANOVA revealed a significant multivariate main effect for target (that is, self, military others, or civilian others) for Bad Idea/Unhelpful, Wilks' $\lambda=.899, F(2,592)=33.36, p<.001$, partial eta squared $=.101$, and for Bad for Career, Wilks' $\lambda=.961, F(2,588)=11.78, p<$ .001 , partial eta squared $=.039$.

Paired t-tests were then conducted to determine which target (self, military others, or civilian others) was perceived by respondents as differing from the others in their attitudes for Bad Idea/Unhelpful and Bad for Career. It was found that respondents perceived more stigma from military others than from civilian others for both Bad Idea/Unhelpful and Bad for Career. Results are presented in Table 13. 
Table 13

Comparisons between Respondents' Ratings of Military and Civilian Others of Treatment-Seeking Stigma Items

\begin{tabular}{lcccc}
\hline & $\underline{\text { Military }}$ & $\underline{\text { Civilian }}$ & & \\
Stigma Item: & $\mathrm{M}(\mathrm{SD})$ & $\mathrm{M}(\mathrm{SD})$ & $t$ & $p$ \\
\cline { 2 - 5 } Bad Idea/Unhelpful & $1.85(0.68)$ & $1.72(0.64)$ & -8.06 & $<.001$ \\
Bad for Career & $1.95(0.85)$ & $1.84(0.76)$ & -5.61 & $<.001$ \\
\hline
\end{tabular}

Note. Bonferroni correction requires a $p$ value of .025 or less to be considered significant.

It was also found that respondents reported significantly higher perceived stigma from military others compared to self-stigma on reports of Bad Idea/Unhelpful, but not for Bad for Career (see Table 14 for results and for means and standard deviations).

Additionally, respondents indicated significantly higher self-stigma compared to perceived stigma from civilian others for both Bad Idea/Unhelpful and Bad for Career (see Table 15 for results and for means and standard deviations).

Table 14

Comparisons between Respondents' Ratings of Self and Military Others of Treatment-Seeking Stigma Items

Self $\quad \underline{\text { Military }}$

Stigma Item:

\begin{tabular}{cccc}
$\mathrm{M}(\mathrm{SD})$ & $\mathrm{M}(\mathrm{SD})$ & $t$ & $p$ \\
\hline $1.80(0.72)$ & $1.85(0.68)$ & 2.35 & 0.02
\end{tabular}

Bad for Career

$1.97(0.90) \quad 1.95(0.85) \quad-0.26 \quad 0.79$

Note. Bonferroni correction requires a $p$ value of .025 or less to be considered significant. 
Table 15

Comparisons between Respondents' Ratings of Self and Civilian Others of Treatment-Seeking Stigma Items

\begin{tabular}{lcccc}
\hline & $\underline{\text { Self }}$ & $\underline{\text { Civilian }}$ & & \\
Stigma Item: & $\mathrm{M}(\mathrm{SD})$ & $\mathrm{M}(\mathrm{SD})$ & $t$ & $p$ \\
\cline { 2 - 5 } Bad Idea/Unhelpful & $1.80(0.72)$ & $1.72(0.64)$ & -3.69 & $<0.001$ \\
Bad for Career & $1.97(0.90)$ & $1.84(0.76)$ & -4.61 & $<0.001$ \\
\hline
\end{tabular}

Note. Bonferroni correction requires a $p$ value of .025 or less to be considered significant.

\section{Relationship between Psychological Symptoms and Perceived Stigma for Treatment-Seeking}

Correlations were run to assess whether symptoms of depression and PTSD were related to reports of perceived stigma for seeking mental health treatment. It was found that reported psychological symptoms for both disorders were significantly correlated with perceived stigma from self, civilian others, and military others (see Table 16). 
Table 16

Correlations between PTSD, Depression, and Perceived Stigma for Treatment-Seeking

Self

$\begin{array}{lll}\text { Bad Idea/Unhelpful } & .10 * & .07 \\ \text { Bad for Career } & .15 * * * & .20 * * *\end{array}$

Civilian Others

$\begin{array}{lll}\text { Bad Idea/Unhelpful } & .11^{* *} & .09 * \\ \text { Bad for Career } & .12 * * & .16^{* * * *}\end{array}$

Military Others

\begin{tabular}{ccc} 
Bad Idea/Unhelpful & $.16^{* * *}$ & $.15^{* * * *}$ \\
Bad for Career & $.16^{* * *}$ & $.20^{* * *}$ \\
\hline$* * * p<.001, * * p<.01, * p<.05$ & &
\end{tabular}

\section{Part 3: Predictors of Treatment-Seeking}

\section{Likelihood of Treatment-Seeking at a V.A. or Non-V.A.}

A paired t-test was conducted to determine whether there was a significant difference in the reported likelihood of seeking treatment at a V.A. versus a non-V.A. facility. It was found that soldiers reported a significantly higher likelihood of seeking treatment at a V.A. $(M=2.50, S D=1.16)$ versus a non-V.A. facility $(M=2.78, S D=$ 1.10), $t(737)=-7.34, p<.001$ ) (with lower scores indicating a higher reported likelihood of seeking treatment). Because soldiers are more likely to seek mental health treatment at a V.A. facility than at a non-V.A. facility, non-V.A. facility treatment-seeking will be excluded from analyses. 


\section{Stigma as a Predictor of Treatment-Seeking}

A multiple regression was conducted to determine whether demographic variables, stigma, or PTSD symptoms were related to the soldiers' reported likelihood of seeking mental health treatment at a V.A. facility. The demographic variables utilized in the analysis included gender, age, race, level of education, and relationship status (single, committed relationship, or widowed/divorced). Stigma items included in the analyses were self-stigma and public stigma of military others for Weak/Incompetent, Dangerous, Bad Idea/Unhelpful, and Bad for Career. Perceived public stigma from civilian others were not included in the analyses because of the findings that perceptions of stigma from self and military others were generally higher than perceptions of stigma from civilian others. Demographic variables were entered into the model first, followed by stigma items, and then PCL-C score.

Results of the analysis indicated that the first step of the model using only demographic variables as predictors was not significant. Therefore, gender, age, race, level of education, and relationship status are not significant predictors by themselves of treatment-seeking at a V.A. However, it was found that the second step of the model was significant, indicating that the stigma items as a set of predictors is associated with soldiers' reported likelihood of seeking treatment at a V.A. facility, $F(5,580)=3.98, p$ $<.001,\left(\mathrm{R}^{2}=.08\right)$. While this model as a whole was significant, none of the stigma items individually were significant predictors of treatment-seeking at a V.A. facility. Inclusion of PTSD symptom report as the third step of the model did not significantly contribute to the overall variance of the model. 


\section{Frequencies of Reported Barriers to Treatment}

Among the 747 soldiers who provided information on the survey, 58 did not respond to questions about barriers. Out of the remaining 689, 236 (34.3\%) endorsed no barriers to treatment-seeking at a V.A. facility, while $221(32.1 \%)$ endorsed no barriers to treatment-seeking at a non-V.A facility. For V.A. treatment-seeking, soldiers reported a mean of $1.43(\mathrm{SD}=1.45)$ barriers, while they reported a mean of $1.69(\mathrm{SD}=1.59)$ barriers to non-V.A. treatment-seeking.

Frequency analyses were conducted to determine how many of the soldiers reported each of the various barriers to seeking treatment and both a V.A. and non-V.A. facility. Results are shown in Table 17. 
Table 17

Number of Soldiers Who Endorsed Each Perceived Treatment Barrier

Barrier:

$\%$

Time Constraints

V.A.

275

39.9

Non-V.A.

265

38.5

Not Understanding Treatment

V.A.

211

30.6

Non-V.A.

212

30.8

Cost of Treatment

V.A.

192

27.9

Non-V.A.

382

55.4

Not Knowing Where to Go

V.A.

Non-V.A.

Transportation

V.A.

Non-V.A.
106

218

31.6

204

29.6

$84 \quad 12.2$

For treatment-seeking at a V.A., soldiers endorsed time constraints most frequently as a barrier, followed by a lack of treatment understanding, not knowing where to go, financial cost of treatment, and transportation difficulties, respectively. For nonV.A. treatment-seeking, the most highly reported barrier was the financial cost, followed 
by time constraints, not knowing where to go, a lack of treatment understanding, and, finally, transportation problems.

Odds ratios were calculated to further examine the differences between barriers at a V.A. facility versus a non-V.A. facility. It was found that respondents were 3.224 times more likely to endorse cost as a barrier to seeking treatment at a non-V.A. facility compared to a V.A. facility. However, they were 1.31 times more likely to endorse transportation as a barrier to treatment-seeking at a V.A. facility compared to a non-V.A. facility. Calculations also revealed that participants rated a similar likelihood of viewing a lack of treatment understanding (odds ratio $=.993$ ), not knowing where to go for treatment (odds ratio $=.909)$, and time constraints (odds ratio $=1.063$ ) as barriers for each type of facility. 


\section{CHAPTER 4}

\section{Discussion}

This study addressed two separate aspects of the process of seeking treatment for a mental illness. First, soldiers were asked about stigma related to admitting that a mental illness is present. If individuals do not admit the presence of a problem or are concerned about the negative consequences of admitting a problem, it is less likely that they will seek the treatment that they may need. Separately, soldiers' concerns about stigma related to the process of actually seeking treatment were examined. Many soldiers may be returning from deployments or leaving the military with the recognition that they may have psychological problems but are not getting treatment. It is therefore important to understand whether this lack of treatment-seeking is related to admitting a problem or whether soldiers are not concerned with admitting a problem but are instead concerned about reaching out to obtain treatment.

Additionally, this study examined self-stigma and public stigma (specifically, whether civilian and/or military others might hold negative views of admitting a mental illness and/or treatment seeking). To address military mental health, it is necessary to understand how soldiers' perceptions of self and others impact their views of mental illness and treatment. It is also informative to understand whether their perceptions of others in the military differ from those of civilian others.

\section{Findings with Regards to Hypotheses}

\section{Concerns about being perceived as weak/incompetent versus dangerous.}

Soldiers were asked to rate how various target groups would view them if they admitted 
the presence of a mental illness. Consistent with hypotheses, respondents were found to perceive more stigma from military superiors and military peers related to weakness than dangerousness. Interestingly, respondents were found to rate civilian friends as perceiving them as more dangerous than weak if they had a mental illness.

Contrary to what was hypothesized, self-stigma scores for weakness/ incompetence and dangerousness were virtually identical. This finding is surprising because of the notion that soldiers are encouraged to focus on strength and toughness. It would be reasonable to think that soldiers would trust themselves to not be dangerous despite having a mental illness simply because they know themselves. Therefore, it would be predicted that concern would come more from associating having a mental illness with being weak or incompetent. It is unclear why this was not the case.

\section{Differences between ratings of various target groups for stigma related to}

having a mental illness. Soldiers were found to rate self, military others, and civilian others differently with regards to stigma for having a mental illness. In line with predictions, for ratings of weakness/incompetence, respondents perceived military others and self to be more stigmatizing than civilian others. Also congruent with hypotheses, soldiers were found to rate military others as more stigmatizing than civilian others for both weakness/incompetence and dangerousness. Inconsistent with hypotheses, it was found that respondents rated themselves and civilian others as holding similar attitudes regarding dangerousness. For the rating of weakness/incompetence, respondents reported the most perceived stigma from military others, followed by self-stigma, and then civilian others. 
Concerns regarding how treatment-seeking is perceived. The hypotheses related to treatment-seeking being perceived as unhelpful versus being bad for one's military career were partially supported. Respondents were found to report that they would view treatment-seeking as bad for their career significantly more than they would report it being a bad idea or unhelpful. Surprisingly, this finding was true for perceptions of the attitudes of family and spouse/partner as well. For ratings of the attitudes of military others, no difference was found for comparisons between perceptions of treatmentseeking being bad for one's military career versus it being a bad idea or unhelpful.

\section{Differences between ratings of each target group for stigma related to}

treatment-seeking. Congruent with hypotheses, soldiers reported more perceived stigma for treatment-seeking among military others than civilian others. For the item assessing whether respondents rated each target group as viewing the treatment-seeking process as a bad idea or unhelpful, military others were perceived to be most stigmatizing, and civilian others were rated as being least stigmatizing of the three groups. Respondents rated themselves as viewing the treatment-seeking process as significantly less of a bad idea or unhelpful compared to military others but significantly more of a bad idea or unhelpful compared to civilian others.

Relationship between self-stigma and public stigma. Although this study assessed perceptions of self-stigma and public stigma separately, the likelihood that these two phenomena affect each other cannot be ignored. As was suggested by Corrigan (2004), it is likely that public stigma can influence self-stigma. It is quite possible that soldiers internalize the views of the military, and with regards to mental illness, soldiers may perceive the military to hold negative stereotypes about those with a mental illness 
and about the treatment-seeking process. Soldiers may then self-stigmatize, possibly viewing themselves as weak, if they perceive military others as sharing these views. Soldiers who are taught to be strong and self-reliant and are exposed to a mentality that discourages seeking help may internalize these views and view themselves as weak if they seek treatment.

It is also possible that self-stigma influences one's perception of public stigma. Soldiers who themselves view mental illness or treatment-seeking negatively may feel that others share these views. Soldiers who are quite invested in their military identity and view having a mental illness as problematic may feel that others in the military would encourage strength and independence rather than relying on others for help. It is unclear which type of stigma may precipitate the other; however, it seems that interventions aimed toward reducing either one would likely help diminish the other.

Treatment-seeking at a V.A. facility. Contrary to what was hypothesized, soldiers reported being significantly more likely to seek mental health treatment at a V.A. facility compared to a non-V.A. facility. This might be related to the financial cost of treatment, as veterans typically have some coverage of costs at a V.A. but would likely need to have private insurance or pay for services at a non-V.A. facility. Indeed, respondents were more than three times as likely to report cost as a barrier to treatment-seeking at a nonV.A. facility compared to a V.A. facility.

The hypotheses regarding stigma and treatment-seeking were somewhat supported, although additional factors related to reported likelihood of treatment-seeking are unclear. It was found that stigma perceived from self and military others as a whole in combination with soldiers' demographic background was a significant predictor of 
reported treatment-seeking at a V.A. facility. However, this combination was found to only partially predict treatment-seeking, with further understanding of contributing factors needed.

This combination of self-stigma, perceived public stigma from military others, and demographic variables was found to be even more predictive of the likelihood of seeking treatment at a V.A. facility among soldiers who report higher levels of PTSD symptoms compared to those who report lower levels. This finding was not consistent with predictions, although it is quite encouraging. It seems that soldiers who are concerned about having a mental illness may be more likely to seek treatment, regardless of whether concerns about stigma are present. These findings support the idea that working to decrease concerns about stigma among soldiers, especially those who may actually be experiencing a mental illness, will likely facilitate lessening the treatment gap that currently exists.

Perceived barriers to treatment. While the findings were simply descriptive in nature, it is important to acknowledge the practical barriers soldiers reported. It is alarming that hundreds of soldiers indicated that a lack of understanding of treatment, not knowing where to go for treatment, and problems with timing, transportation, and/or costs associated with treatment may prohibit them from seeking help. Additionally, while the cost of treatment may make it more likely for veterans to seek help at a V.A. facility compared to a non-V.A. facility, the treatment-seeking process may be thwarted by a lack of adequate transportation to a V.A. facility. Improved communication between mental health providers/facilities and soldiers returning from deployment about available 
resources, what treatment might entail, and soldiers' concerns about treatment may increase the likelihood of treatment-seeking for some individuals.

\section{Implications of Findings}

These findings have important implications not only for military service members but for mental health professionals as well. That perceived stigma was found to be related to a lower likelihood of treatment-seeking is not surprising. Closer examination and better understanding of the relationship between perceived stigma and the process of admitting a mental illness and actually engaging in treatment is vital to improve mental health in the military.

The finding that soldiers reported highest perceived stigma from military others related to the association between having a mental illness and weakness/incompetence is quite troubling. As Nash (2007) indicated, exemplary soldiers are viewed as those who emanate strength and competence. Those who are enveloped in the military culture, such as those who are on active duty status, may feel more pressure to meet these ideals. If soldiers are concerned that admitting a mental illness is in direct conflict with military others' expectations of them with regard to strength and competence, this may lead to the decision to maintain perceived military standards at the expense of psychological health by ignoring symptoms. Moreover, fear of being viewed as weak by superiors, who are in a position of power and authority over soldiers, may be a considerable barrier to admitting and, in turn, seeking treatment for a mental illness.

It is of additional concern that soldiers were found to report more perceived selfstigma than perceived public stigma from civilian others for ratings of weakness/incompetence. It seems plausible that, due to their having spent the previous 
year on active duty status and therefore surrounded by military personnel, their views of themselves may have been influenced by this. The fact that respondents were more likely to trust that civilian others would be less stigmatizing than they would be of themselves with regards to weakness/incompetence is quite suggestive of the barrier to addressing mental health concerns that many soldiers may encounter.

While it is discouraging that soldiers perceive more stigma from military others and from themselves with regards to weakness/incompetence, it is promising that, following deployment, National Guard soldiers return to civilian life. If they are less likely to view civilian others as associating having a mental illness with weakness/incompetence, it may be that their perceptions of military others' attitudes become less influential with more time spent in civilian life. This would likely be especially true for those who are less invested in their military identity or who do not plan to continue serving once their terms of service are complete.

The finding that military others were rated as being the most likely to associate having a mental illness with dangerousness is likely to pose a significant barrier to admitting a psychological problem, especially while soldiers are still involved in the military. With military training and deployment necessarily involving the use of weapons, being perceived as dangerous due to a mental illness would certainly be problematic in the military, particularly while serving in a combat zone. Soldiers are often going on missions that already pose significant safety risks, so concern that other members of the military may feel more unsafe serving next to a fellow soldier with a mental illness is likely to contribute to a soldier's avoidance of addressing psychological problems. 
If soldiers are accurate in their perception that other military members would view them as dangerous if they had a mental illness, the reluctance to admit a problem would likely lead to the decision to avoid treatment-seeking. This may lead to an unfortunate reinforcement of the belief that those with a mental illness are dangerous in that psychological symptoms are found to be linked to cognitive deficits (e.g., Barrett et al., 1996; Vasterling et al., 2002). In the case that a soldier is experiencing problems in attention, concentration, or other cognitive processes due to symptoms of a mental illness, it may compromise certain military operations and put oneself and others at risk. With certain military operations that require sustained attention (e.g., keeping guard on military bases, operating specialized weapons or machinery), there is little room for error, and improper execution of the task could have harmful or fatal consequences. This suggests that recognition and, more importantly, proper treatment of a mental illness among military personnel is critical.

With regards to the perceptions of how treatment-seeking would be perceived, it is quite problematic that respondents were more likely to view the process as detrimental to their military career than to view it as being a bad idea or unhelpful. Again due to the fact that these individuals were active duty at the time of the study, their high level of involvement in the military culture may lead to more focus on their identity as soldiers than on psychological health. If treatment-seeking may have a negative impact on their military career, soldiers who are invested in their military identity will likely not engage in this process.

It is interesting that respondents were more likely to rate civilian others (family, spouse/partner) as viewing treatment-seeking as bad for one's military career than being 
unhelpful or a bad idea. It seems that those soldiers who return to civilian life and are more limited in their military involvement may be encouraged by family members to seek help. It may be that these soldiers are less concerned about the impact treatmentseeking may have on their military career if they are less invested in their military identity. This, in combination with family members being perceived as viewing the process as helpful, may facilitate one's decision to seek treatment.

While it is possible that lower investment in one's military identity may aid the treatment-seeking process, it is probable that those who are quite invested in their identity as a soldier would be more reluctant to seek help. Indeed, military others were perceived to be the most stigmatizing in their views of treatment-seeking. Therefore, those who are quite concerned about how they would be perceived by military others would be likely to avoid treatment-seeking for fear of being stigmatized. Additional concern arises from the finding that soldiers rated military others and themselves similarly with regards to the perception of treatment-seeking being bad for one's military career. However, the finding that civilian others were found to be least stigmatizing in their views of treatment-seeking may have a positive effect on soldiers in their decision-making process once they return to civilian life, if they feel they would be supported in their treatment-seeking. Indeed, Warner et al. (2008) found that soldiers identified encouragement from family and friends as a way to overcome concerns about stigma and to engage in treatment-seeking.

The findings related to stigma and mental health provide support to the findings of past research assessing stigma in the military. Britt's (2000) study showing that members of the military are more likely to be reticent to admit a psychological problem compared to a medical problem provides insight into the concerns military personnel may have with 
how they may be perceived if they have psychological concerns. The finding that soldiers in this study were concerned about being perceived as weak extends findings of other research as well; Hoge et al. (2004) and Warner et al. (2008) found that this concern was a reported barrier to treatment-seeking among military members, as were concerns that others would have less confidence in them, that treatment-seeking could harm one's career, and that leaders or others in the military may treat them differently.

The findings of this study have implications for mental health care providers as well. Concerns about the perceptions of self and others for both having a mental illness and for treatment-seeking pose a considerable barrier to accessing psychological treatment. Mental health care providers, especially those at V.A. facilities, must be aware of this in order to help facilitate the process of treatment-seeking.

Within a V.A. system, mental health care providers have an opportunity to reach out to veterans who are already seeking some type of treatment because of the nature of the hospitals and how psychological and medical treatment are usually available at the same location. If psychologists, social workers, psychiatrists, or other mental health professionals have an understanding of the difficulties those with psychological problems may be facing in their decision to address psychological health, this may influence their approach to getting veterans in for treatment.

One approach that may facilitate the treatment-seeking process among those being served at a V.A. facility involves integration of medical and psychological care. Educating other health care providers, such as primary care doctors, may allow a collaborative approach to mental health treatment. For instance, if physicians are sensitive to instances when a physical complaint may have a psychological component, a 
readiness to consult with a mental health care provider at a veteran's primary care appointment may allow access to mental health treatment under the guise of a medical appointment, possibly allowing less of a concern about being stigmatized. Educating primary care providers about mental health symptoms is a crucial step in connecting veterans with the care they need. Indeed, primary care providers have been found to identify mental illness at low rates despite symptoms being present (Liebschutz et al., 2007). Even more problematic, it has been estimated that $70 \%$ of primary care visits are driven by a psychological concern (Bruns \& Johnson, 1999). It therefore seems that medical appointments are a prime opportunity to improve access to mental health treatment for those who have been in the military and who may be concerned about admitting a psychological problem.

Another consideration for mental health care professionals is how outreach programs are conducted for those returning from deployment. It is crucial for V.A. providers to be in contact with those conducting outprocessing procedures so as to address concerns about stigma when soldiers are returning from war. Encouragement from military superiors may be especially helpful in moving soldiers towards the decision to address their psychological health. During outprocessing procedures is also an opportune time for soldiers to learn about services available to them and how the V.A. system works. Given that some soldiers reported concerns such as cost of health care and not understanding treatment at the V.A., setting aside time for V.A. providers to talk with soldiers may be a way to improve access to psychological treatment.

Additionally, these findings suggest that it is important for mental health professionals to approach those who have decided to seek treatment with great 
sensitivity. Among those with higher reported levels of PTSD symptoms, the link between perceived stigma and likelihood of not seeking treatment was significant. It therefore may be that those who are experiencing significant levels of psychological symptoms and decide to come in for treatment are doing so with the concern that seeking treatment could have negative consequences. It is quite likely that the barriers an individual may overcome in order to obtain treatment could remain as obstacles and make it difficult for treatment to continue; for instance, a soldier who seeks treatment may be concerned that this will be found out by others every time he or she attends a therapy session. Processing these concerns and working with soldiers to recognize the impact that mental health problems can have on functioning and quality of life may help to motivate them to continue working towards improved psychological health despite barriers.

Furthermore, the findings suggest that it is important for clinicians to consider involving family members in treatment, if appropriate. Because civilian others may be perceived as more supportive and less stigmatizing than military others, family and friends can be an important part of a soldier's readjustment to civilian life and to therapeutic progress. Family members' involvement in a soldier's treatment could provide a soldier with the support and encouragement that he or she may need to overcome barriers that may be encountered.

A final consideration for mental health professionals who are treating soldiers is related to other external barriers that soldiers reported. It may be useful for clinicians to work with their facilities to make treatment as accessible and flexible as possible. For instance, if time constraints are preventing some soldiers from seeking treatment, 
ensuring that mental health care providers are available outside of typical work hours may be valuable for V.A. facilities and veterans. Soldiers who are readjusting to civilian life and hold jobs during weekdays may find that group or individual therapy that is held in the evenings is a feasible option for treatment.

\section{Findings with Regards to Other Research}

The findings of this study expand those of previous studies that have demonstrated soldiers' and veterans' concern about stigma related to mental health concerns. Sayer et al. (2009) showed that reported perceived public stigma related to mental health treatment-seeking discouraged those enrolled for care at a VA from seeing a mental health professional. Specifically, veterans were found to express concern about being rejected by employers and peers because they perceived others as viewing those who seek psychological treatment as weak, incompetent, or "crazy." These findings by Sayer et al. are similar to concerns expressed by soldiers in the present study, who indicated some concern over military superiors and peers viewing them as weak or incompetent.

Concerns about public stigma have been echoed in other research among military personnel and veterans as well. Ouimette et al. (2011) showed that veterans identified stigma concerns as barriers to treatment-seeking at V.A. facilities more than they identified practical barriers, such as transportation or financial difficulties. These stigma concerns included both perceived self-stigma (e.g., "I would think less of myself for needing help") and perceived public stigma (e.g., "I don't want to look stupid for not knowing how to figure these problems out").

The findings of the present study are consistent with previous findings in that they suggest that stigma concerns may hinder the treatment-seeking process among veterans. 
Indeed, concerns of public stigma have repeatedly emerged in research findings. However, studies generally have not distinguished between concerns of military others versus civilian others. This distinction appears to be an important one, as soldiers in the present study indicate varying levels of perceived stigma with the different groups.

In addition to stigma concerns, the finding that practical barriers may hinder treatment-seeking among many soldiers is consistent with past findings as well. Hoge et al. (2004) and Stecker et al. (2007) showed that many members of the military report barriers related to time constraints, cost, and other logistic concerns, as the soldiers in the present study expressed. The finding that approximately a third of respondents indicated that time constraints and lack of information related to treatment (not knowing where to go, what treatment entails) may interfere with seeking treatment suggests that members of the military are encountering significant barriers to mental health. Furthermore, the finding that about half the participants reported that financial cost may prevent them from seeking help at a non-V.A. facility suggests that they may not seek help because they feel they cannot afford it. Therefore, while stigma appears to contribute to soldiers' decision to refrain from seeking mental health treatment, practical barriers appear to play a significant role in this decision as well.

\section{Study Limitations}

One limitation of this study is that, although it was an examination of stigma, it was an assessment of each soldier's perception of what others might think rather than an assessment of what those individuals actually think. This perception of others' attitudes is an important aspect of the treatment-seeking process to understand, since this likely plays a role in whether an individual addresses mental health problems; however, it would be 
valuable to explore the actual attitudes of the various target groups in addition to the perceived attitudes.

Another limitation of this study is that the data were collected immediately following deployment as soldiers were gathered together in large groups. The timing did not allow the respondents much time to readjust to being back home after serving overseas, as they are likely to experience significant changes as they readjust to civilian life. Moreover, the specific timing of the data collection (amidst several mental health briefings) may have influenced responses. Furthermore, responses may have been affected by a lack of privacy as soldiers completed the survey packets. On questions assessing how others might perceive soldiers if mental health problems arise, soldiers may be concerned that those individuals whose attitudes are being rated can see their answers. Of note, some respondents did verbally ask the researchers to verify that their answers were confidential, which indicates some level of concern about others viewing their responses.

A third limitation of the study is that two of the three individual items for each type of stigma (having a mental illness, treatment-seeking) were very highly correlated, indicating that they were essentially measuring the same construct. It therefore might be more informative to identify another possible area of concern related to stigma to be assessed rather than examining two aspects of stigma that are so significantly related. For instance, for stigma related to admitting the presence of a mental illness, a third area of stigma that might contribute to understanding of soldiers' perceptions of others' attitudes might involve the idea of blaming the individual with a mental illness. For stigma related to treatment-seeking, it might be informative to assess whether this act is rated as being 
perceived as weak, as asking for help may go against the values of self-reliance and independence that are often associated with the military. Further exploration of what constructs stigma comprises might lead to much-needed clarification about how perceptions of stigma impact one's willingness to admit and/or seek treatment for a psychological problem.

An additional limitation of the study is that the sample is fairly limited in several ways. First, it includes only soldiers from a National Guard unit, who, when not deployed, report for military duty periodically. These findings therefore are not generalizable to soldiers who are active duty and work within the military context on a daily basis. These service members were also only from an Army unit, and it is unknown whether their reports of stigma would be comparable to those of individuals in other branches of the military. Additionally, there were few female soldiers who participated relative to male soldiers, although this is not unexpected, given the proportion of male to female soldiers throughout the military. The majority of the sample was also somewhat lacking in racial diversity, as the majority of respondents were Caucasian. Furthermore, it is unknown what rank the respondents were. It would be useful to have an understanding of whether the individuals completing the surveys were higher or lower ranking and whether this is related to reports of perceived stigma or likelihood of seeking treatment. Therefore, future research with a more diverse sample and more information about the respondents would likely be informative to better understand stigma concerns among individuals from varying demographic backgrounds. 


\section{Directions for Future Research}

The present study addresses important questions related to military mental health and what may be preventing soldiers from admitting and/or seeking treatment for a mental illness. However, much remains to be understood about how stigma may interfere with soldiers' recognition of and obtaining treatment for a psychological problem. One way in which future studies could provide a better understanding of concerns about stigma and mental illness is through attempting to assess soldiers at different times throughout the deployment process. It would be useful to understand whether and how perceptions of stigma may change from pre-deployment to post-deployment.

Furthermore, consideration of assessing soldiers both immediately upon return, as well as following a readjustment period in which soldiers have reintegrated into their civilian lives may prove useful in illuminating how immersion in the military culture can change one's views of mental health and treatment-seeking.

This study also demonstrates the importance of future research addressing how one's level of investment in his or her military identity may impact perceptions of stigma and how this may relate to treatment-seeking. Furthermore, research related to this would benefit from gathering information on one's military background for comparisons of perceptions of stigma. Knowledge of soldiers' rank and length of time in the military, for instance, could be useful in understanding how one's military identity and exposure to military culture impacts perceptions of stigma. Inclusion of this information may contribute substantially to understanding how one's involvement in the military may relate to how mental health is addressed. 
Another valuable direction for future research in this area would be the inclusion of actual assessment of how military and civilian others perceive mental illness and treatment-seeking in addition to soldiers' perceptions of others' attitudes. While understanding soldiers' perceptions is important to understand, clarifying whether these perceptions are congruent with actual reports of stigma may help clarify where mental health professionals and military officials can intervene to aid the treatment-seeking process. It may be that military and civilian others would not view having a mental illness or treatment-seeking in a negative light; if this is indeed the case, as Porter and Johnson (1994) suggested, then it seems that providing education to soldiers on the differences between their perceptions and what is actually reported may be beneficial.

Despite the limitations, the findings of this study provide some insight into the question of why many soldiers returning from war are not seeking treatment despite elevated rates of mental illness. The findings support the notion that stigma concerns are related to more than just the perception of how others might view an individual with a mental health concern. Instead, it is necessary to understand more fully and evaluate separately how self and various categories of others stigmatize or are perceived as stigmatizing. Additionally, addressing concerns about stigma related to having a mental illness versus that for seeking treatment can provide further clarification of what is contributing to the treatment gap among military personnel. These different aspects of stigma are important to distinguish so that future research can allow a better understanding of what specifically is interfering with addressing psychological concerns among soldiers and veterans. Better comprehension of the process of admitting and seeking treatment for a mental illness among military personnel, as well further 
knowledge of perceived barriers, may allow for improved access to mental health care. Bridging the gap between needing and obtaining mental health treatment is vital in order to improve the psychological health of those individuals who have willingly served the country despite the extraordinary, stressful, and, at times, traumatic experiences they may encounter during their time in the military. 


\section{REFERENCES}

American Psychiatric Association. (1952). Diagnostic and statistical manual of mental disorders. Washington, DC: Author.

American Psychiatric Association. (1980). Diagnostic and statistical manual of mental disorders $\left(3^{\text {rd }}\right.$ ed. $)$. Washington, DC: Author.

Barrett, D. H., Green, M. L., Morris, R., Giles, W. H., \& Croft, J. B. (1996). Cognitive functioning and posttraumatic stress disorder. American Journal of Psychiatry, 259, 2701-2707.

Bell, J. B., \& Nye, E. C. (2007). Specific symptoms predict suicidal ideation in Vietnam combat veterans with chronic post-traumatic stress disorder. Military Medicine, 172, 1144-1147.

Bolton, E. E., Lambert, J. F., Wolf, E. J., Raja, S., Varra, A. A., \& Fisher, L. M. (2004). Evaluating a cognitive-behavioral group treatment program for veterans with posttraumatic stress disorder. Psychological Services, 1, 140-146.

Britt, T. (2000). The stigma of psychological problems in a work environment: Evidence from the screening of service members returning from Bosnia. Journal of Applied Social Psychology, 30, 1599-1618.

Bruns, D., \& Johnson, R. (1999). Understanding the Opportunities of Integrated Primary Care. The Health Psychologist, 21, 14-19.

Carden, M. J. (2010, January 13). Mullen voices concern with military suicide rate. American Forces Press Service. Retrieved from http://www.af.mil/news/story.asp?id=123185434.

Corrigan, P. W. (2004). How stigma interferes with mental health care. American Psychologist, 59, 614-625.

Corrigan, P. W., \& Penn, D. L. (1999). Lessons from social psychology on discrediting psychiatric stigma. American Psychologist, 54, 765-776.

Corrigan, P. W., \& Watson, A. C. (2002). The paradox of self-stigma and mental illness. Clinical Psychology: Science and Practice, 9, 35-53.

Corrigan, P. W., \& Kleinlein, P. (2005). The impact of mental illness stigma. In P. W. Corrigan (Ed.), On the stigma of mental illness: Implications for research and social change (pp. 11-44). Washington: The American Psychological Association. 
Cully, J. A., Tolpin, L., Henderson, L., Jimenez, D., Kunik, M. E., \& Petersen, L. A. (2008). Psychotherapy in the veterans health administration: Missed opportunities? Psychological Services, 5, 320-331.

Department of Defense. (2008). Vietnam Conflict - Casualty summary. Retrieved from http://siadapp.dmdc.osd.mil/personnel/CASUALTY/vietnam.pdf.

Department of Defense. (2011). Operations Enduring Freedom, Iraqi Freedom, and New Dawn Casualty Summary by State - As of June 20, 2011. Retrieved from http://siadapp.dmdc.osd.mil/personnel/CASUALTY/state_oef_oif.pdf.

Department Of Defense Task Force on the Prevention of Suicide by Members of the Armed Forces. (2010, August). Final report of the Department of Defense Task Force on the Prevention of Suicide by Members of the Armed Forces. Retrieved October 27, 2010 from http://www.health.mil/dhb/downloads/Suicide\%20Prevention\%20Task\%20Force \%20final\%20report\%208-23-10.pdf.

Department of Veterans Affairs Office of Inspector General. (2007). Healthcare inspection: Implementing VHA's mental health strategic plan initiatives for suicide prevention (Report No. 06-03706-126). Retrieved from http://www.va.gov/oig/54/reports/vaoig-06-03706-126.pdf.

Erbes, C., Westermeyer, J., Engdahl, B., \& Johnsen, E. (2007). Post-traumatic stress disorder and service utilization in a sample of service members from Iraq and Afghanistan. Military Medicine, 172, 359-363.

Foy, D. W., Sipprelle, R. C., Rueger, D. B., \& Carroll, E. M. (1984). Etiology of posttraumatic stress disorder in Vietnam veterans: analysis of premilitary, military, and combat exposure influences. Journal of Consulting and Clinical Psychology, 52, 79-87.

Friedman, M. J., Resick, P. A., \& Keane, T. M. (2010). PTSD: Twenty-five years of progress and challenges. In M. J. Friedman, T. M. Keane, \& P. A. Resick (Eds.), Handbook of PTSD: Science and practice (pp. 3-18). New York, NY: Guilford Press.

Green-Shortridge, T. M., Britt, T. W., \& Castro, C. A. (2007). The stigma of mental health problems in the military. Military Medicine, 172, 157-161.

Hoge, C. W., Auchterlonie, J. L., \& Milliken, C. S. (2006). Mental health problems, use of mental health services, and attrition from military service after returning from deployment to Iraq or Afghanistan. Journal of the American Medical Association, 295, 1023-1032. 
Hoge, C. W., Castro, C. A., Messer, S. C., McGurk, D., Cotting, D. I., \& Koffman, R. L. (2004). Combat duty in Iraq and Afghanistan, mental health problems, and barriers to care. New England Journal of Medicine, 351, 13-22.

Hoge, C. W., Terhakopian, A., Castro, C. A., Messer, S. C., \& Engel, C. C. (2007). Association of posttraumatic stress disorder with somatic symptoms, health care visits, and absenteeism among Iraq war veterans. American Journal of Psychiatry, $164,150-153$.

Jordan, B. K., Schlenger, W. E., Hough, R. L., Kulka, R. A., Weiss, D. S., Fairbank, J. A., \& Marmar, C. R. (1991). Lifetime and current prevalence of specific psychiatric disorders among Vietnam veterans and controls. Archives of General Psychiatry, 48, 207-215.

Kaplan, M. S., Huguet, N., McFarland, B. H., \& Newsom, J. T. (2007). Suicide among male veterans: a prospective population-based study. Journal of Epidemiology and Community Health, 61, 619-624.

Lapierre, C. B., Schwegler, A. F., \& LaBauve, B. J. (2007). Posttraumatic stress and depression symptoms in soldiers returning from combat operations in Iraq and Afghanistan. Journal of Traumatic Stress, 20, 933-943.

Liebschutz, J., Saitz, R., Brower., V., Keane, T. M., Lloyd-Travaglini, C., Averbuch, T., $\&$ Samet, J. H. (2007). PTSD in urban primary care: High prevalence and low physician recognition. Journal of General Internal Medicine, 22, 719-726.

McFall, M. E., Mackay, P. W., \& Donovan, D. M. (1992). Combat-related posttraumatic stress disorder and severity of substance abuse in Vietnam veterans. Journal of Studies on Alcohol, 53, 357-363.

Milliken, C. S., Auchterlonie, J. L., \& Hoge, C. W. (2007). Returning from the Iraq war among active and reserve component soldiers longitudinal assessment of mental health problems. Journal of the American Medical Association, 298, 2141-2148.

Monson, C. M., Friedman, M. J., \& La Bash, H. A. J. (2007). A psychological history of PTSD. In M. J. Friedman, T. M. Keane, \& P. A. Resick (Eds.), Handbook of PTSD: Science and practice (pp. 37-52). New York, NY: Guilford Press.

Nash, W. P. (2007). Combat/operational stress adaptations and injuries. In C. R. Figley \& W. P. Nash (Eds.), Combat stress injury: Theory, research, and management (pp. 33-63). New York: Routledge.

Nelson Goff, B. S., Crow, J. R., Reisbig, A. M. J., \& Hamilton, S. (2007). The impact of individual trauma symptoms of deployed soldiers on relationship satisfaction. Journal of Family Psychology, 21, 344-353. 
Ouimette, P. C., Finney, J. W., \& Moos, R. H. (1997). Twelve-step and cognitivebehavioral treatment for substance abuse: A comparison of treatment effectiveness. Journal of Consulting and Clinical Psychology, 65, 230-240.

Ouimette, P., Vogt, D., Wade, M., Tirone, V., Greenbaum, M. A., Kimerling, R., Laffaye, C., Fitt, J. E., \& Rosen, C. S. (2011). Perceived barriers to care among Veterans Health Administration patients with posttraumatic stress disorder. Psychological Services, 8, 212-223.

Owens, G. P., Herrera, C. J., \& Whitesell, A. A. (2009). A preliminary investigation of mental health needs and barriers to mental health care for female veterans of Iraq and Afghanistan. Traumatology, 15, 31-37.

Porter, T. L., \& Johnson, W. B. (1994). Psychiatric stigma in the military. Military Medicine, 159, 602-605.

Rauch, S. A., Defever, E., Favorite, T., Duroe, A., Garrity, C., Martis, B., \& Liberzon, I. (2009).Prolonged exposure for PTSD in a Veterans Health Administration PTSD clinic. Journal of Traumatic Stress, 22, 60-64.

Ready, D. J., Thomas, K. R., Worley, V., Backscheider, A. G., Harvey, L. A. C., Baltzell, D., \& Rothbaum, B. O. (2008). A field test of group based exposure therapy with 102 veterans with war-related posttraumatic stress disorder. Journal of Traumatic Stress, 21, 150-157.

Samuelson, K. W., Neylan, T. C., Metzler, T. J., Lenoci, M., Rothlind, J., Henn-Haase, C., ...Marmar, C. R. (2006). Neuropsychological functioning in posttraumatic stress disorder and alcohol abuse. Neuropsychology, 20, 716-726.

Sayer, N. A., Friedemann-Sanchez, G., Spoont, M., Murdoch, M., Parker, L. E., Chiros, C., \& Rosenheck, R. (2009). A qualitative study of determinants of PTSD treatment initiation in veterans. Psychiatry, 72, 238-255.

Sayers, S. L., Farrow, V. A., Ross, J., \& Oslin, D. W. (2009). Family problems among recently returned military veterans referred for a mental health evaluation. Journal of Clinical Psychiatry, 70, 163-170.

Schrimsher, G. W., Parker, J. D., \& Burke, R. M. (2007). Relation between cognitive testing performance and pattern of substance use in males at treatment entry. The Clinical Neuropsychologist, 21, 498-510.

Stecker, T., Fortney, J. C., Hamilton, F., \& Ajzen, I. (2007). An assessment of beliefs about mental health care among veterans who served in Iraq. Psychiatric Services, $58,1358-1361$. 
Stretch, R. (1985). Post-traumatic stress disorder among US Army Reserve Vietnam and Vietnam-era veterans. Journal of Consulting and Clinical Psychology, 53, 935-936.

Taft, C. T., Kaloupek, D. G., Schumm, J. A., Marshall, A. D., Panuzio, J., King, D. W., \& Keane, T. M. (2007). Posttraumatic stress disorder symptoms, physiological reactivity, alcohol problems, and aggression among military veterans. Journal of Abnormal Psychology, 116, 498-507.

Tanielian, T., Jaycox, L. H., Adamson, D. M., \& Metscher, K. N. (2008). Introduction. In T. Tanielian \& L. H. Jaycox (Eds.), Invisible wounds of war: Psychological and cognitive injuries, their consequences, and services to assist recovery. (pp. 3-17). Santa Monica: RAND Corporation.

van der Kolk, B. A. (2010). The history of trauma in psychology. In M. J. Friedman, T. M. Keane, \& P. A. Resick (Eds.), Handbook of PTSD: Science and practice (pp. 1936). New York, NY: Guilford Press.

Vasterling, J. J., Duke, L. M., Brailey, K., Constans, J. I., Allain, A. N., \& Sutker, P. B. (2002). Attention, learning, and memory performances and intellectual resources in Vietnam veterans: PTSD and no disorder comparisons. Neuropsychology, 16, 5-14.

Wagner, T. H., Harris, K. M., Federman, B., Dai, L., Luna, Y., \& Humphreys, K. (2007) Prevalence of substance use disorders among veterans and comparable non-veterans from the National Survey on Drug Use and Health. Psychology Services, 4, 149-157.

Weathers, F. W., Litz, B. T., Herman, D. S., Huska, J. A., \& Keane, T. M. (1993). The PTSD Checklist (PCL): Reliability, validity, and diagnostic utility. Paper presented at the Annual Meeting of the International Society for Traumatic Stress Studies, San Antonio, TX.

Warner, C. H., Appenzeller, G. N., Mullen, K., Warner, C. M., \& Grieger, T. (2008). Soldier attitudes toward mental health screening and seeking care upon return from combat. Military Medicine, 173, 563-569.

Zivin, K., McCarthy, J. F., McCammon, R. J., Valenstein, M., Post, E. P., Welsh, D. E., \& Kilbourne, A. M. (2008). Health-related quality of life and utilities among patients with depression in the Department of Veterans Affairs. Psychiatric Services, 59, 1331-1334. 


\section{Appendix A}

DIRECTIONS: While answering the following, please imagine that you are experiencing some mental health problem such as depression, anxiety, substance use, PTSD, or other problems. If you were to decide that you had a mental health problem, how would the following people view you? If you were to seek treatment, how would they view you doing that?

\begin{tabular}{|c|c|c|c|c|c|}
\hline \multicolumn{2}{|l|}{ If I } & \multirow{2}{*}{$\begin{array}{c}\begin{array}{c}\text { Strongly } \\
\text { agree }\end{array} \\
\text { SA }\end{array}$} & \multirow{2}{*}{$\begin{array}{c}\text { Agree } \\
\text { A }\end{array}$} & \multirow{2}{*}{$\begin{array}{c}\text { Disagree } \\
\text { D }\end{array}$} & \multirow{2}{*}{$\begin{array}{c}\begin{array}{r}\text { Strongly } \\
\text { disagree }\end{array} \\
\text { SD } \\
\end{array}$} \\
\hline \multirow{3}{*}{$\begin{array}{l}\text { I would view myself } \\
\text { as... }\end{array}$} & Strong & & & & \\
\hline & $\begin{array}{r}\text { Competent or } \\
\text { Capable }\end{array}$ & SA & A & $\mathrm{D}$ & SD \\
\hline & Dangerous & SA & A & $\mathrm{D}$ & $\mathrm{SD}$ \\
\hline \multirow{3}{*}{$\begin{array}{l}\text { Military superiors } \\
\text { would view me as... }\end{array}$} & Strong & $\mathrm{SA}$ & A & $\mathrm{D}$ & $\mathrm{SD}$ \\
\hline & $\begin{array}{r}\text { Competent or } \\
\text { Capable }\end{array}$ & SA & A & $\mathrm{D}$ & SD \\
\hline & Dangerous & SA & A & $\mathrm{D}$ & $\mathrm{SD}$ \\
\hline \multirow{3}{*}{$\begin{array}{l}\text { My family of origin } \\
\text { (parents, siblings) } \\
\text { would view me as... }\end{array}$} & Strong & $\mathrm{SA}$ & $\mathrm{A}$ & $\mathrm{D}$ & SD \\
\hline & $\begin{array}{r}\text { Competent or } \\
\text { Capable }\end{array}$ & SA & A & $\mathrm{D}$ & SD \\
\hline & Dangerous & SA & A & $\mathrm{D}$ & $\mathrm{SD}$ \\
\hline \multirow{3}{*}{$\begin{array}{l}\text { Military peers } \\
\text { would view me as... }\end{array}$} & Strong & $\mathrm{SA}$ & $\mathrm{A}$ & $\mathrm{D}$ & SD \\
\hline & $\begin{array}{r}\text { Competent or } \\
\text { Capable }\end{array}$ & SA & A & $\mathrm{D}$ & SD \\
\hline & Dangerous & SA & A & $\mathrm{D}$ & SD \\
\hline \multirow{3}{*}{$\begin{array}{l}\text { Friends who are not } \\
\text { in the military } \\
\text { would view me as... }\end{array}$} & Strong & $\mathrm{SA}$ & $\mathrm{A}$ & $\mathrm{D}$ & SD \\
\hline & $\begin{array}{r}\text { Competent or } \\
\text { Capable }\end{array}$ & SA & A & $\mathrm{D}$ & SD \\
\hline & Dangerous & SA & A & $\mathrm{D}$ & $\mathrm{SD}$ \\
\hline \multirow{3}{*}{$\begin{array}{l}\text { Military } \\
\text { subordinates would } \\
\text { view me as... } \\
\text { (Skip this item if not } \\
\text { applicable.) }\end{array}$} & Strong & SA & A & $\mathrm{D}$ & SD \\
\hline & $\begin{array}{r}\text { Competent or } \\
\text { Capable }\end{array}$ & SA & A & $\mathrm{D}$ & SD \\
\hline & Dangerous & SA & $\mathrm{A}$ & $\mathrm{D}$ & SD \\
\hline \multirow{3}{*}{$\begin{array}{l}\text { My spouse/romantic } \\
\text { partner would view } \\
\text { me as... (Skip this } \\
\text { item if not } \\
\text { applicable.) }\end{array}$} & Strong & SA & A & $\mathrm{D}$ & $\mathrm{SD}$ \\
\hline & $\begin{array}{r}\text { Competent or } \\
\text { Capable }\end{array}$ & SA & $\mathrm{A}$ & $\mathrm{D}$ & $\mathrm{SD}$ \\
\hline & Dangerous & $\mathrm{SA}$ & A & $\mathrm{D}$ & SD \\
\hline
\end{tabular}




\begin{tabular}{|c|c|c|c|c|c|}
\hline \multicolumn{2}{|c|}{$\begin{array}{l}\text { If I were to seek professional } \\
\text { treatment for a mental illness (for } \\
\text { example, from a psychiatrist, } \\
\text { psychologist, counselor, therapist, } \\
\text { etc.) ... }\end{array}$} & \multirow{2}{*}{$\begin{array}{c}\begin{array}{c}\text { Strongly } \\
\text { agree }\end{array} \\
\text { SA }\end{array}$} & Agree & Disagree & $\begin{array}{l}\text { Strongly } \\
\text { disagree }\end{array}$ \\
\hline & A good idea & & A & $\mathrm{D}$ & $\mathrm{SD}$ \\
\hline $\begin{array}{l}\text { I would view me } \\
\text { seeking treatment }\end{array}$ & Helpful & SA & A & $\mathrm{D}$ & $\mathrm{SD}$ \\
\hline as... & $\begin{array}{r}\text { Bad for my } \\
\text { military career }\end{array}$ & SA & A & $\mathrm{D}$ & SD \\
\hline \multirow{3}{*}{$\begin{array}{l}\text { Military superiors } \\
\text { would view me } \\
\text { seeking treatment } \\
\text { as... }\end{array}$} & A good idea & SA & A & $\mathrm{D}$ & SD \\
\hline & Helpful & SA & A & $\mathrm{D}$ & SD \\
\hline & $\begin{array}{r}\text { Bad for my } \\
\text { military career }\end{array}$ & SA & A & $\mathrm{D}$ & SD \\
\hline \multirow{3}{*}{$\begin{array}{l}\text { My family of origin } \\
\text { would view me } \\
\text { seeking treatment } \\
\text { as... }\end{array}$} & A good idea & SA & A & $\mathrm{D}$ & SD \\
\hline & Helpful & SA & A & $\mathrm{D}$ & SD \\
\hline & $\begin{array}{r}\text { Bad for my } \\
\text { military career }\end{array}$ & SA & A & $\mathrm{D}$ & SD \\
\hline \multirow{3}{*}{$\begin{array}{l}\text { Military peers would } \\
\text { view me seeking } \\
\text { treatment as... }\end{array}$} & A good idea & SA & A & $\mathrm{D}$ & SD \\
\hline & Helpful & SA & A & $\mathrm{D}$ & $\mathrm{SD}$ \\
\hline & $\begin{array}{r}\text { Bad for my } \\
\text { military career }\end{array}$ & SA & A & $\mathrm{D}$ & SD \\
\hline \multirow{3}{*}{$\begin{array}{l}\text { Friends not in the } \\
\text { military would view } \\
\text { me seeking treatment } \\
\text { as... }\end{array}$} & A good idea & SA & A & $\mathrm{D}$ & SD \\
\hline & Helpful & SA & A & $\mathrm{D}$ & SD \\
\hline & $\begin{array}{r}\text { Bad for my } \\
\text { military career }\end{array}$ & SA & A & $\mathrm{D}$ & SD \\
\hline \multirow{3}{*}{$\begin{array}{l}\text { Military subordinates } \\
\text { would view me } \\
\text { seeking treatment as... } \\
\text { (Skip this item if not } \\
\text { applicable.) }\end{array}$} & A good idea & SA & A & $\mathrm{D}$ & $\mathrm{SD}$ \\
\hline & Helpful & SA & A & $\mathrm{D}$ & SD \\
\hline & $\begin{array}{r}\text { Bad for my } \\
\text { military career }\end{array}$ & SA & A & $\mathrm{D}$ & $\mathrm{SD}$ \\
\hline \multirow{3}{*}{$\begin{array}{l}\text { My spouse/romantic } \\
\text { partner would view } \\
\text { me seeking treatment } \\
\text { as... (Skip this item if } \\
\text { not applicable.) }\end{array}$} & A good idea & SA & A & $\mathrm{D}$ & $\mathrm{SD}$ \\
\hline & Helpful & SA & A & $\mathrm{D}$ & SD \\
\hline & $\begin{array}{r}\text { Bad for my } \\
\text { military career }\end{array}$ & SA & A & $\mathrm{D}$ & $\mathrm{SD}$ \\
\hline
\end{tabular}




\section{Appendix B}

DIRECTIONS: If you decided that you would seek treatment, you might consider obtaining it either from a VA or from a non-government facility. Please indicate whether these issues might discourage you from obtaining treatment in these settings. (Check all boxes that apply.)

\section{VA Facility}

$\square$ The financial cost of treatment

$\square$ Transportation problems

$\square$ Not understanding what treatment involves

$\square$ Time constraints (getting off of work, limited hours)

$\square$ Not knowing where to go

\section{Non-Government Facility}

$\square$ The financial cost of treatment

$\square$ Transportation problems

$\square$ Not understanding what treatment involves

$\square$ Time constraints (getting off work, limited hours)

$\square$ Not knowing where to go 